\title{
Un conjunto de pinturas de Pedro Rodríguez de Miranda
}

\author{
María Teresa Jiménez Priego
}

Pedro Rodríguez de Miranda es un pintor tan importante como poco conocido ${ }^{1}$. Nació y murió en Madrid (1698-1766). Sus padres fueron Pedro Rodríguez y Lorenza García de Miranda, hermana del pintor de Cámara del rey Felipe V, Juan García de Miranda. En el taller de su tío se formó en el arte de la pintura y de la restauración, y con él pasó su vida, primero como discípulo y después como colaborador y ayuda.

Era de temperamento apacible, íntegro, sereno y generoso. Su habilidad en la pintura lo condujo a grandes éxitos y lo introdujo en el mundo artístico oficial y popular, además del de las Congregaciones religiosas - como la de los Clérigos Menores, Carmelitas-, iglesias, etc.

En Palacio fue presentado por su tío Juan García de Miranda y el P. Aller (confesor del Infante D. Felipe), de cuyo favor gozó. Desarrolló su actividad durante tres reinados sucesivos -el de Felipe V, Fernando VI y Carlos III- Llegó, en 1742, a solicitar la futura de la plaza de Pintor de Su Majestad, plaza para la que se le propone por el Duque de la Mirándola ante el Rey dos años después.

Pedro Rodríguez se distinguió como pintor de temas religiosos, paises, bambochadas y fábulas, y aún cultivó esporádicamente el retrato. Sobresaliendo principalmente en la labor de restauración de las pinturas de Palacio.

1 Sobre su vida y actividades artísticas, ver María Teresa JIMENEZ, "Los Miranda, pintores madrileños del siglo xVIII, Anales del Instituto de Estudios Madrileñcs. T. XV. Madrid, CSIC, 1978, pág. 255-278, y "Artistas de las Reales Caballerizas. Il", en la misma Rev. (en prensa). 
Mas no es nuestra pretensión detenernos en la amplia y diversa labor artística de este pintor sino en un conjunto de cuadros que responden al gusto y la espiritualidad del momento y por su conservación in situ tienen una importancia relevante como documento histórico de un ambiente; porque, como el mismo Mâle ${ }^{2}$ expresa "es raro que una obra ocupe su verdadero lugar».

Se trata de los cuatro grandes lienzos que Pedro Rodríguez de Miranda pintó para la capilla de Santa Teresa de los Carmelitas descalzos de esta Corte, pertenecientes a la historia del profeta Elías ${ }^{3}$.

Dicha capilla de Santa Teresa se abre a la izquierda del crucero de la iglesia ${ }^{4}$ que fuera la conventual de Carmelitas descalzos, del Monasterio de San Hermenegildo, en la calle Alcalá, de Madrid, inaugurado en 1605. Esta iglesia, desde 1836 (en que se expulsó a los frailes), fue ocupada por la actual Parroquia de San José.

La capilla tiene planta central trebolada (fig. 1) y las exedras laterales se decoran con los cuatro lienzos de Pedro Rodríguez de Miranda, objeto de nuestro estudio, que fueron hechos ex profeso para la capilla y al parecer con la distribución en que se conservan. El lienzo se adapta a la forma semicircular del muro. Queremos subrayar que, tanto estos lienzos como el resto de la decoración de la iglesia y la capilla, son esencialmente de temas carmelitanos ${ }^{5}$, aludiendo a la Orden que hizo el encargo.

2 L'Art religieuX du XVI/ siècle. París, 1972, pág. 430-431 y Madrid 1985, pág. 370.

3 Cean, Diccionario. Madrid, 1800 (1965), IV, pág. 222. Ponz, Viaje, Madrid, 1793. T. V., n. ${ }^{\circ} 27$, pág. 260-261. ToRmo, Iglesias del antiguo Madrid. Madrid 1972 (1927), págs. 194-199.

${ }^{4}$ La iglesia es todavía, en todo lo arquitectónico, la conventual, afirma Tormo (obra citada, pág. 194). La capilla especial de Santa Teresa, se supone creada por D. Rodrigo Calderón, marqués de Siete Iglesias, pero que, por resultar pequeña, se derribó en 1646 para construir otra sobre planos del Hermano Bautista o Fray Lorenzo de San Nicolás, según escribe el Conde DE POLENTINOS (Investigaciones madrileñas. Madrid 1948, pág. 111).

Tormo opina que dicha capilla debió ser pintada (en su decoración conservada) con bastante posterioridad a su construcción. Tomo, obra citada, pág. 196 (Iglesias, pág. 196).

5 El arte de los siglos XVII y XVIII debe mucho a las Ordenes religiosas. Después del Concilio de Trento se inaugura, con ellas, una nueva iconografía, un nuevo sentido de esta iconografía y una nueva época artistica.

Ésto nos lo confirma el número de iglesias conventuales existentes a fines del siglo XVIII, que superaban en número y riqueza a las parroquiales. Ceán (obra citada T. IV, págs. 101 y ss.) nos da los datos de Sevilla y Madrid, ciudades en las que existian 26 iglesias parroquiales frente a 60 conventuales, y 21 frente a 70 , respectivamente.

Gracias al esplendor de las Ordenes religiosas de este período postconciliar y del siglo siguiente se manifiesta la creatividad de un sinnúmero de artistas españoles y extranjeros al "servicio" de jesuitas y franciscanos. (Esta misma apreciación hace Guillet de Saint- 
En la capilla todos los símbolos y temas del Carmelo están allí representados, tanto en obras escultóricas como pictóricas, ya sea sobre el muro o sobre el lienzo. Todas estas creaciones parecen responder a un orden programático preestablecido. Las estatuas de San Elías, Eliseo y Santa Teresa, junto a San Juan Bautista, que ornan los altares, hablan de las distintas facetas de la Orden: de la primera fundación (S. Elías), de su continuidad (Eliseo y San Juan Bautista) y de la reforma de la Orden (con la gran Santa de Ávila). Todo se halla ensamblado de forma similar a como aparece en las portadas del libro de la Reforma del Carmelo, de 1655, y el de la Historia general profética de la Orden de Nuestra Señora del Carmen, de 1641, y aún más en el Speculum Carmelitanum, que es la obra capital con estos contenidos, impresa en Amberes en 1680 (figs. 2 a 5).

Completa el conjunto de la capilla y las pinturas de Miranda, a la entrada, un lienzo de Juan Peña, a la izquierda, que se afronta a otro de Pablo Pernicharo, a la derecha, con escenas del profeta Elías. Sobre las pechinas de la cúpula, Luis González Velázquez representó al fresco a Débora, Esther, la reina de Saba y Abigail, prefiguración de la Virgen. Otros cuatro lienzos anónimos pequeños, de forma oblonga, que inmortalizan individualmente a santas carmelitas, ornan los muros centrales de las pilastras que sostienen la cúpula ${ }^{6}$.

Georges en sus memorias inéditas, según nos comenta Mâle, obra citada, pág. 509.

La creación de estos artistas no era personal ni espontánea, sino que respondía a las exigencias e ideas programáticas que dichas órdenes y congregaciones les imponían, ya no sćlo en cuanto al tema sino en cuanto a su desarrollo y emplazamiento. Esta premeditación en estas realizaciones no era original de esta época, pues ya era conocida en la Edad Media y en el Renacimiento.

Hasta tal punto esto era manifiesto que, a través de la decoración, el fiel era consciente de a quién pertenecía la iglesia en que se encontraba. Ante una Circuncisión pensaba en una Iglesia de jesuitas, y ante un San Elias en una del Carmelo. Subrayamos, de nuevo, que habia una perfecta sucesión de las escenas y el emplazamiento de ellas les daba su verdadero sentido.

Todos estos considerandos hoy son difícilmente apreciables y los sentimientos que en su momento pudieron suscitar han quedado diluidos, dado que en su gran mayoria, y como consecuencia de la desamortización, la francesada y la guerra civil, se han visto privados de su primigenia concepción y ubicación. Muchos lienzos fueron arrancados de los retablos o altares, otros fueron vendidos, algunos destruidos y ios que se consideraron mejores pasaron a Museos públicos, como el de la Trinidad, en España, de donde salieron, como legado, en depósito, hacia Museos, iglesias o entidades diferentes de aquellos lugares para los que habian sido concebidos.

Estos conjuntos podian tener un carácter religioso, monástico, palatino u hospitalario. Entre los dos primeros se clasifican estos de los que nos ocupamos en este artículo.

- ToRmo, obra citada, pág. 197. 
Culmina el ciclo con los cuatro grandes cuadros de Pedro Rodríguez de Miranda, firmados en $1745^{7}$, dato que nos permite fechar dicha decoración, en conjunto, hacia la mitad del siglo XVIII.

Este conjunto que estudiamos, de hacia 1745, cabría compararlo con la decoración del Sagrario de la Cartuja de Granada, que es uno de los más acabados ejemplos de conjunto alegórico en España (de 1712). Ambos muestran la evolución producida durante el siglo XVII en tales obras hasta concluir en estas alegorias, agradables y pomposas, como un panegírico en honor del santo al que se dedican. Este ejemplo será seguido y abre las puertas al rococó de las grandes abadías e iglesias de la Europa central ${ }^{8}$.

Dentro de este complejo artístico la mayor relevancia la tienen los lienzos de Miranda, de las exedras, iguales y de grandes dimensiones (2 $\times 1,75 \mathrm{~m}$ aproximadamente). Están dedicados a escenas de la vida del Fundador de la Orden, San Elías ${ }^{9}$. En la exedra de la izquierda se hallan los lienzos de "Elías anunciando a Acad la sequía" y "El profeta vaticinando la muerte de Ococías». "Elías alimentado por un ángel» y la "Resurrección del hijo de la viuda de Sarepta», son los temas de los de la derecha.

Estos lienzos de la capilla de Santa Teresa nos seleccionan las principales escenas de la vida de San Elías, contrastando con otros conjuntos pictóricos en los que se reproduce el desarrollo de los extensos ciclos que ilustran su vida ${ }^{10}$. Esta selección hay que pensar que vino impuesta por las escasas dimensiones de la citada capilla.

\footnotetext{
María Elena Gómez MOREnO, “Adición” en TORMo, obra citada, pág. 199.

J. Gallego, Visión y simbolos en la pintura española del siglo de Oro, Madrid. Aguilar, 1972 (París 1968), pág. 203.

9 Elías es la figura más grande del Antiguo Testamento, después de Moisés. Es el fundador de la Orden Carmelitana, cuyos principios se remontan al siglo $1 \times 0 \times$ antes de Cristo.

De la figura de San Elías, sus fuentes, ciclos e iconografia se ocupa, principalmente, Louis REAU en Les études carmelitaines, Brouwer, 1956, "Elie le prophète I. Selon les écritures et les traditions chrétiennes", en el apartado "L'Iconographie du prophète Elie", pág. 233-267. Y también en Iconographie de l'Art chrétien. Paris 1955, II, 1, pág. 347-359. De especial importancia es el estudio de Daniel DE LA VIERGE-MARIE, Speculum Carmelitanum. Anvers 1680. Interesantes son las aportaciones de Emile MALE, L'Art Religieux du $X V I^{\circledR}$ siècle. Armand Colin. Paris, 1972, pág. 443-454, y Ferrano RoIG, Iconografía de los Santos, Barcelona, Omega, 1950, pág. 92-93, junto a SCHOECKEL, "San Elías. 29 de julio" Año Cristiano, BAC. Madrid 1959, t. III, pág. 180-184 y Francesco NEGRi ARNoloI «Iconografía", pág. 210-212, de Santos del Carmelo de Ludovico SAGGI, Madrid, 1982, (Roma 1972.)

10 No existe, al parecer, ningún conjunto esculpido sobre la leyenda y vida de San Elias. Por el contrario, las series pintadas y grabadas son relativamente numerosas. La
} 
La figura de Elias aparece en todas las escenas vestido con el hábito marrón y capa blanca, semejante a un manto de pelo (I $R, I, 8)$, revelándose como religioso carmelita. Pedro Rodríguez de Miranda ha preferido poner de relieve su Patronazgo sobre la Orden a mostrarlo como precursor de San Juan Bautista, vistiendo la indumentaria de penitente. El representarlo vestido de carmelita responde al gusto que, desde el siglo XIII, se hizo cada vez más frecuente en el arte de Occidente, de acuerdo con los deseos de los religiosos que lo tenían por su primer fundador.

Lleva la cabeza calva y nutrida barba tradicional, mas no porta ninguno de los atributos habituales.

Las escenas que se representan en este conjunto de Madrid son las más usuales. Vamos a analizar en detalle estos temas iconográficos que han sido pensados por algún teólogo, cuya elección impuso al artista, sus instrucciones y programas, al mismo tiempo que, quizá, le proporcionó el encargo.

Las fuentes de estos temas son bíblicas, tanto judias como cristianas; y aun literarias, pues Elías ocupa un lugar destacado en los Libros de los Reyes. Hace relación también al Nuevo Testamento, dado que Elías reaparece en los Evangelios Sinópticos tanto en la Transfiguración del Señor (a la que asiste con Moisés) como en el Apocalipsis de San Juan (donde es asociado a Enoch).

Nos fijaremos y haremos relación a las fuentes más explicitas y más directas; las de los Libros de los Reyes. La correspondencia entre diferentes pasajes de estos textos y los cuatro lienzos de Miranda más los dos de Peña y Pernicharo, nos manifiesta el carácter histórico-bíblico de estas pinturas. $Y$ en este sentido vamos a hacer el comentario de ellas. No seguimos el esquema de los ciclos que hace Réau ${ }^{11}$, porque estas

\footnotetext{
mayor parte de las series pintadas datan del siglo XVII y han sido ejecutadas para Conventos Carmelitas o iglesias dedicadas a San Elias.

Entre ellas podemos dictar los frescos de la iglesia del profeta Elias, en Jaroslavl, Moscovia; San Martín de los Montes, en Roma, decorada por dieciocho frescos de Gaspar Dughet, sobrino de Poussin; los veinte lienzos de los carmelitas calzados de Barcelona, obra de Pedro Cuquet (entre 1636 y 1645); una serie de frescos le había sido consagrada en el claustro de Santa María del Carmen, en Nápoles; las pinturas de Valdés Leal en la iglesia del Carmen de Córdoba; las pinturas de Despax en la capilla de los carmelitas de Toulouse; la cúpula de la capilla del Carmen Descalzo de Paris (Instituto Católico).

Sobre el particular, ver REAU, "L'Iconographie du prophète Elie", Les études carmelitaines, Brouwer, 1956, pág. 246 y ss. MALE, El Barroco, "La decoración de las iglesias. Las iglesias de las Ordenes religiosas", Madrid 1985 (Paris 1932), pág. 375-376.

11 "l. Elie dans l'Ancien Testament", Les études carmelitaines, Brouwer, 1956, pág. 234-236.
} 
escenas no se corresponden plenamente a ellos. Seguimos el orden cronológico de la vida del profeta, dado en el texto bíblico, y en él haremos alusión a las posibles afinidades con dichos ciclos y las connotaciones de prefiguración de Cristo y simbologías que puedan encerrar.

Mas antes hemos de fijarnos en que la disposición de los lienzos es en aspa, no contigua, es decir, el cuadro primero y cuarto decoran la exedra izquierda, y el segundo y tercero la derecha - como se presenta en el esquema del plano-. Esta colocación no se relaciona con la sucesión cronológica. El doblez que algún lienzo presenta, nos indica la posibilidad de haber sido levantados y guardados en algún momento difícil —como el de la desamortización, guerra civil, etc.-. Posteriormente, al restituirlos a su emplazamiento, se les ha dado otra disposición diferente a la original.

\section{ELIAS ANTE ACAB}

Elías predice a Acab, infiel a Yahvé, un largo período de sequia, sin rocío ni lluvia (I Reyes, XVII, 1).

Acab, rey de los territorios del norte de Israel, casa con Jezabel, que introduce el culto a los dioses fenicios, fundamentalmente el de Baal. Este hecho trae consigo la persecución y muerte de los sacerdotes de Yahvé.

El momento recogido en el lienzo es aquel en el que el profeta Elías se presenta ante Acab y le anuncia que, debido a sus pecados e infidelidades al Dios de Israel, habrá un largo período de sequia, sin lluvia y $\sin$ tan siquiera rocío (fig. 6).

El rey ostenta todos los atributos de poder para reafirmar su realeza: corona, cetro, está sentado en un rico trono adornado de rocalla, sobre podium de amplias molduras. Parece estar entronizado bajo un baldaquino encuadrado por robustas columnas estriadas, entre las que se extiende un amplio cortinón rojo, recogido a la derecha, según los usos tradicionales de la época.

El ademán del rey es arrogante y su pose espectacular. Unos soldados armados con casco y lanza, abundante servidumbre, caballeros entre los que ondea la enseña de su reino, un perro fiel a sus pies y los muros de su palacio rematados en esculturas, de fondo, completan la 
expresión de poder, solidez y fuerza con la que quiere impresionar al profeta.

Contrastando con esta insolente arrogancia, Elías, descalzo, de pie, en actitud movida como de paso y con pobre indumentaria, increpa al rey en nombre de Yahvé y le anuncia las futuras desdichas de sequía y hambre.

El lienzo tiene el sentido teatral del espectáculo concebido como "lenguaje visual» inteligible a todos, lenguaje que domina la vida española del siglo XVII y se continúa en el XVIII. Es el que se mantiene en tantas pinturas de esta época, priva en la vida española y brilla sobre todo en las esferas monárquica y religiosa. Pedro Rodríguez de Miranda no se muestra en esto creador, pero si sabe, con maestría, aceptar los gustos tradicionales.

La concordancia y proximidad de esta pintura con otras pinturas y grabados de la época pone de relieve la tiránica importancia, en esos momentos, de una cultura gestual, teatral, que se manifiesta por el ademán, el gesto, el signo establecido, pero también por el emblema, el símbolo. Lo que rodea al rey está empapado de un sentido trascendental ${ }^{12}$.

Y para que el cuadro sea más un placer para los ojos que una moraleja -en contraposición a lo que les sucedía a los Jerónimos de El Escorial- vamos a contemplar en él, además, otros valores estéticos y de composición.

Las esculturas marfileñas o alabastrinas, cuyas siluetas se recortan sobre el cielo azul y rematan los muros del fondo, evocan "la casa de maríl que el rey edificó" y "todas las ciudades que fortificó" durante su reinado (I $R, X X \mid I, 39)$. La destacada elevación del rey sobre un friso de figuras en que, a la derecha, se desarrolla la escena, nos habla de su grandeza.

La regia belleza de Acad, subrayada por la larga y rubia caballera y su rizada barba, es otro signo de majestad, evidente en esa época, aunque en la nuestra sea inimaginable. La idea de sosiego viene dada por la actitud estatutaria del rey, y es acrecentada por la presencia de las columnas que dan la sensación de aparato inamovible y escenográfico.

12 Pfandl habla del ceremonial español reflejado en nuestra pintura, el cual es recogido por GaLlego, Visión y simbolos de la pintura española del siglo xVI, Madrid, Aguilar, 1972, pág. 143, 147-148. 
Otros accesorios, como el collar real, que pende de su cuello, el cortinaje que a Francastel recuerda el dosel de un trono y es signo de grandeza, junto a los tonos rojos que salpican principalmente la zona ocupada por el rey y en su proximidad, simbolizan gozo, rango y solemnidad.

El dosel o cortinaje marca, divide el espacio en que el rey se muestra y vive, en comunicación con el palacio y la fortaleza, un espacio cerrado, en contraposición con el espacio abierto en el que se desarrolla el resto de la escena.

El profeta se encuentra en la zona de unión entre esos dos espacios, se muestra en una actitud de tránsito, fugaz, expresando su austeridad y sacrificio en su áspero sayal, y su humanismo y servicio voluntario en la desnudez de sus pies.

Próximo a él, en primer plano, un perro acecha sus movimientos, con lo que indica tanto la fidelidad (en este caso al rey) de que es símbolo, como alude al ejercicio noble de la caza practicada por el magnate que cierra la composición y descansa su mano sobre el bastón, luciendo en su cintura - como el rey y su guardia - una banda roja, signo de rango y distinción (como ya hemos anotado). También este can podría aludir al pasaje bíblico en que se expresa cómo los perros lamerán la sangre de Acad (I R, XXI, 19).

Otro elemento retórico utilizado por el artista es el lenguaje de «las manos", tan ponderado y comentado en El Greco y en tantos otros pintores flamencos, españoles o italianos. Toda Europa emplea esa gesticulación, ese manoteo para expresar sus sentimientos, en los siglos XVII y xVIII. El teatro, la ópera van a multiplicar hasta el hastío las miradas declamatorias o las manos separadas del cuerpo... Rodríguez Miranda ha estudiado en todos los personajes con esmero su ademán, pero principalmente ha cuidado la colocación de las manos del rey y del profeta, en forma igual y contrapuesta, marcando con ellas y sus respectivas cabezas el rombo que encierra el punto de mayor interés del lienzo.

Desde el punto de vista compositivo debemos comentar distintos aspectos. Predomina el carácter de «friso", el más apto para narraciones históricas. Sin embargo, la diagonal - marcada por el perro, Elías y el rey- divide el cuadro en dos mitades de caracteres diferentes, a la vez que da a la escena un matiz de crescendo hacia la derecha y hacia la parte superior. En el triángulo de la izquierda se suceden las numerosas figuras, marcando distintos planos, pero sin poner especialmente ninguna de relieve, a excepción discreta del profeta. Contrariamente, en la parte de la derecha, la figura del rey, con su carácter monolítico y absoluto lo 
llena todo, pues, hasta los dos soldados armados que irrumpen desde casi la penumbra en el ángulo inferior, sólo sirven para realzarla más.

La "luz", que sigue principalmente la línea de las figuras y de la diagonal, subraya aún más estas características.

Si consideramos la composición dividida verticalmente, casi en su mitad, observamos que, a la izquierda, se suceden zonas de espacio, figuras y cielo abierto, contrastando con el único espacio en vertical, de la derecha, ocupado por la figura del rey.

La ordenación jerárquica de los elementos componentes, así como la distribución compositiva parecen responder al momento histórico en que se pintó el lienzo y a la filosofía dominante de la época. Fue creado en el siglo de las luces, en los momentos de exaltación de la realeza y de no perfecto entendimiento entre la fe y la razón, entre la monarquía y la iglesia.

En resumen, la idea maestra de esta pintura es la oposición entre la vida consagrada al placer de los sentidos y al poder, y la dedicada a la vida del espiritu.

Si buscamos los antecedentes o versiones iconográficas del pasaje encontraremos, con sorpresa, que Réau y Mâle en ninguno de sus estudios citados lo recoge, y por lo tanto no cita reproducciones del mismo. En cambio, sí aparece en el Speculum Carmelitanum ${ }^{13}$ (fig. 7).

El encuentro tiene lugar (en este grabado) en el momento en que el rey Acad, acompañado de su ejército y servidores, ofrece un sacrificio sobre el altar elevado ante la estatua de Baal. Respetuosamente tiene la cabeza descubierta, dejando sobre el graderío del altar el turbante con la corona y el cetro, manteniendo el armiño y el collar real, amén de la espada ceñida a la cintura. El profeta interrumpe el acto de culto para anunciarle el castigo que se le seguiría por su infidelidad a Yahvé.

La pintura de Pedro Rodríguez de Miranda representa un momento algo posterior en el tiempo, y en un escenario que le permite mayor ostentación y evoca sus hazañas constructivas y de fortificación. La escena como tal creemos responde a esquemas tradicionales, de otras pinturas y grabados, pero que el artista ha renovado parcial o totalmente. Asi, podemos citar obras como la de A. Veneziano "Castigo de Elimas" (fig. 8), o el grabado de Raimondi (fig. 9) con el «Martirio de Santa

13 Obra citada, Cap. IV, pág. 56, lám. 4. 
Cecilia» ${ }^{14}$ y la pintura de José Jiménez Donoso ${ }^{15}$. Pudieron servirle de inspiración, entre otros muchos, los grabados de la serie de "Samuel" de G. de lodi excudit - M. de Vos inventor ${ }^{16}$, por ejemplo el número 3 en la composición del trono y acompañamiento de soldados y súbditos, así como los números 128,131 ó 141. Más próximo aún resulta el 216, sobre Nabucodonosor, pero invertido.

Este tipo de trono, como suerte de apoteosis, es frecuente en pinturas y grabados de estos siglos de plenitud de la monarquia y por ello las fuentes pueden estar muy diluidas y ser múltiples.

\section{ELÍAS RESUCITA AL HIJO DE LA VIUDA DE SAREPTA}

Según la predicción de Elías se sucedieron años de sequía total. Yahvé ordenó al profeta marchar junto al torrente Kerit, al este del Jordán. Allí tendría agua, $y$, a través de unos cuervos, recibiría pan y carne cada día (I Reyes, XVII, 2-6). Al quedar seco también el torrente, Yahvé indicó a Elías dirigirse a Sarepta de Sidón, donde una viuda lo alimentaría (I R, XVII, 7-17). A cambio de sus cuidados, Elías resucita al hijo de la viuda, que murió durante su estancia en la ciudad (I $R, X V I I, 17-24)$.

Cada una de estas escenas es fuente de inspiración para representaciones pictóricas o grabados. Generalmente éstas adornan los textos sinópticos con datos, a veces, tomados de la Vulgata. Tal es el caso de la búsqueda de leña que realizan madre e hijo para cocer al fuego su pan (como narra el Libro I de los Reyes) y cómo ella recoge dos trozos de madera en forma de cruz (adición de la Vulgata). En las representaciones los dos trozos de madera simbólicos están generalmente dispuestos como collar, en forma de cruz de San Andrés. Otras veces, sin embargo, es una cruz como la del Salvador, que ella tiene entre sus manos, como observa Réau ${ }^{17}$.

14 Recogidos por Ana ÁvILA PADRON en «Rafael en la pintura y escultura española del siglo $\times V \mid$ " $A E A, 1974$, pág. 58-88.

${ }^{15}$ "Fundación de la Orden Mercedaria", en el Museo de Bellas Artes, de Valencia.

16 Biblioteca Nacional de Madrid, Sala de Estampas, ER 1380.

1 Iconographie de l'Art chrétien, París 1956, T. II, 1, pág. 351-353. 
La pintura de Rodríguez de Miranda (fig. 10) que comentamos no nos recoge estos detalles, sí, en cambio, alude a ellos en la disposición, en forma de cruz de San Andrés del cuerpo muerto del hijo de la viuda, cuyo antecedente podria encontrarse en el grabado de Abraham Blomero (fig. 11) inventor - Joan Saerdam excudebat ${ }^{18}$, en el que Elías, a la entrada de la ciudad, halla a madre e hijo en el trabajo descrito, formando con sendos leños - el de la viuda y su hijo- la referida cruz.

En otras versiones grabadas ${ }^{19}$ se yuxtaponen las dos escenas: la del encuentro en la ciudad y el momento en que Elías, echado sobre el niño en la cama, tras su invocación a Yahvé, le devuelve la vida. Y aún se añade, en un segundo término, (en la lámina 7 del Speculum) (fig. 12) el momento en que, por la oración del profeta, aumenta el aceite y la harina de la viuda hospitalaria.

Más próxima a la creación de Pedro Rodríguez de Miranda es la serie de la Historia de San Elias, de Collaert, que se custodia en nuestra Biblioteca Nacional ${ }^{20}$, que tratan de forma diferente el momento de la resurrección del joven.

En realidad, el texto bíblico hace referencia a dos o tres momentos bien diferenciados: el llanto por el hijo muerto o petición de ayuda a Elias, la oración del profeta a Yahvé y la acción directa que le devuelve la vida.

El lienzo de la capilla de Santa Teresa nos ofrece la plasmación de los dos primeros anteriormente citados. Yuxtapone ambas acciones en un esquema o composición más simple, pero similar e invertida, a la que contemplamos en el lienzo de "Elías ante Acad" (el primero de la serie que estudiamos). A la derecha, sobre el lecho, yace, en forma de cruz de San Andrés (según el simbolismo trazado con los dos leños, que crea la Vulgata), el cuerpo del hijo muerto. Junto a él, la madre viuda llora desconsolada. La acompañan otras dos mujeres, que, con ademán compungido, expresan su dolor. A la izquierda, de pie, secundando el deseo de la madre, Elías implora la gracia del cielo para recuperar al hijo. La luz y la gracia poderosa se manifiesta en unos rayos luminosos que inciden sobre Elias. Con este poder recibido obraría el milagro y recompensaría la generosidad de la madre.

\footnotetext{
18 Grabado núm. 43267 y 41925 de la Sala de Estampas de la Biblioteca Nacional de Madrid.

19 Lámina 7 del Speculum y la 149 del ER 1380 de la Biblioteca Nacional de Madrid.

20 Concretamente los números 163 y 164, del ER 1380. Diseñados por M. de Vos y grabados por Collaert.
} 
La escena se desarrolla en un interior, como nos manifiestan los muros y pilastras de fondo. Sin embargo, los grandes vanos que relacionan el espacio exterior e interior, dan a la escena un carácter ambivalente ${ }^{21}$.

Al crear este espacio ambivalente el artista quiere «jugar" con esa ambigüedad para dar mayor capacidad a ambos, para, con igual facilidad aproximarnos esos planos reales de la muerte y alejar ese otro en el que el profeta se adentra en la comunicación con el Altísimo, o aquellas lejanías creadas como una especulación.

El esquema compositivo se desarrolla en torno a dos líneas oblicuas - la descrita por el profeta y por el cuerpo yacente-, que le dan movimiento y acción, los cuales son acompasados por la serenidad transmitida por las verticales del fondo. Por otra parte, el artista vuelve a contrastar el espacio ocupado por una figura - la principal del relato, Elías-, que se presenta con los brazos abiertos y traza con su cuerpo también la cruz de San Andrés, con la acción más sedentaria, de más figuras, con carácter casi de friso, que arranca del primer plano, próximo al espectador, y dejando un vacío espectacular en altura, que podría significar la oscuridad y pesantez del dolor. Elías, arrancando de un segundo plano y elevándose en altura evoca la esperanza y la vida.

Según la tradición, la resurrección del hijo de la viuda es la prefiguración de la resurrección de Lázaro o del mismo Cristo. Halló eco, entre los pintores, desde el siglo III, en los frescos de la sinagoga de DouraEuropos, hasta nuestros días.

\section{EL PROFETA ELÍAS SOCORRIDO POR EL ÁNGEL EN EL DESIERTO}

El desafío que Elías había lanzado a los sacerdotes de Baal para demostrarles la ineficacia de sus ídolos y la grandeza de Yahvé, seguido de la muerte de los sacerdotes (IR, XVIII, 16-46 y XIX, 1-2) enojó a Jezabel, que se prometió perseguir al profeta y darle muerte. Temiendo Elias por su vida huyó al desierto y deseó morir (I R, XIX, 3-8). Se acostó

21 Gallego, obra citada. 
y se durmió bajo un enebro. Un ángel lo despertó y le dijo: ¡Levántate y come! Miró y vio a su cabecera una torta cocida sobre piedras calientes y un jarro de agua. Comió y se volvió a acostar. Por segunda vez fue despertado por el ángel. Reconfortado con la frugal comida anduvo durante cuarenta días y cuarenta noches hasta el monte Horeb, el monte de Dios.

Este temas es uno de los preferidos por la simbología cristiana desde la Edad Media ${ }^{22}$. La popularidad de la escena se explica por la riqueza de su simbolismo. Es un tema a la vez eucarístico, cristólogico y mariano. Los teólogos ven en él una prefiguración de La Cena y así lo inserta Santo Tomás de Aquino en el Oficio del Santísimo Sacramento. Por otra parte, Elías desesperado, invocando a la muerte y consolado por un ángel, es considerado como el símbolo de Cristo en la agonia del huerto de los Olivos. Finalmente, el profeta alimentado por un mensajero celeste prefigura a la Virgen alimentada en el Templo por los ángeles ${ }^{23}$.

Entre las representaciones más reconocidas podemos citar los frescos de la catedral de Orvieto, del siglo XIV; el tríptico de La Cena de Dierik Bouts, así como las obras de Luini (Brera, Milán), Tintoretto (Scoula di S. Rocco, Venecia), el grabado de Leonardo Gaultier (que simultanea la escena del ángel y la marcha del profeta en una misma escena), la conocida de Valdés Leal dentro del conjunto del convento de carmelitas de Córdoba; el cartón para una de las 15 tapicerías de Rubens consagradas al "Triunfo de la Eucaristía", el cuadro de Felipe de Champaigne pintado para Val de Grâce, el grabado número 13 del Speculum (fig. 13), y ya en el siglo XVIII, por no citar sino dos: el techo del palacio arzobispal de Udine, pintado por Tiépolo y el lienzo de San José, por Rodríguez de Miranda (fig. 14), en el que centramos nuestra atención especialmente.

Este cuadro de la capilla de Santa Teresa está concebido de acuerdo con la filosofía y estética de la época, y, tanto el escenario, en que tiene lugar la acción, como la concepción del espacio y vestuario responden a la formación de Rodríguez de Miranda, como artista de corte y a la vez religioso.

22 MALE, obra citada, pág. 447.

23 REAU, Iconographie, II, 1, pág. 353-354 y Les études carmelitaines, 1956, "Elie nourri par un ange dans le désert", pág. 254-256. 
La representación del espacio es la utilizada en los siglos XVII y XVIII. Es un espacio tridimensional, que sitúa en primer término las figuras principales y evoca, por sucesión de luces, sombras y colores la perspectiva infinita del fondo - tanto la coloreada de donde parece proceder el ángel, como la luminosa, teñida de verdes de esperanza, hacia donde Elías debe dirigirse, y por ello se abre junto a él, a la izquierda.

Es, según esto, también, un espacio simbólico que une el espacio real con el figurado o insinuado, cargado de intencionalidad y connotaciones al unísono con las vivencias de su ambiente "barroco".

A su vez, no consideramos que este espacio sea escénico, sino que evoca el espacio real en el que tiene lugar la acción, en plena naturaleza. No obstante, hemos de tener en cuenta que esa naturaleza y ese paisaje responden a "montajes" de taller a partir, como mucho de notas tomadas de la realidad. Sabido es que esta pintura en directo, no se realizaria sino un siglo después.

El esquema compositivo es el de dos diagonales que se cortan en el centro del lienzo, el cual precisamente está marcado por la cabeza del profeta, subrayando la importancia de éste. El ritmo del cuadro es ascendente, impreso por la actitud de Elías y la del ángel, que se inclina hacia éste y describe con su cuerpo, miembros y alas, otras dos diagonales llenando casi todo el espacio del ángulo superior derecho creando una mayor sensación del movimiento.

El tiempo podemos considerarlo expresado en sus facetas de pasado, presente y futuro. Un pasado aludido en la pose dormida del profeta, de la que sale en ese presente de vigilia al que es llamado. Y el futuro está insinuado y evocado en el camino luminoso por el que se le invita a marchar.

La escena se desarrolla sin relación a ninguna otra, dando una nota de modernidad, frente a la representación grabada de Gaultier del siglo XVII, que, en la yuxtaposición de escenas, refleja las influencias medievales que aún perviven en su espíritu y en su obra.

La relación que la pintura obra de Rodriguez Miranda tenga con las que hemos citado y otras de las que hablaremos, no es muy estrecha. Compositivamente está más cerca del lienzo de "San Pedro liberado por el ángel» de Murillo, del Ermitage, en Leningrado (fig. 15), que de las restantes. Se repite el esquema en diagonal, disposición de las figuras y compensación de vanos y volúmenes. 
El grabado de Gaultier ${ }^{24}$ (fig. 16) y el de Lommelin ${ }^{25}$, junto a la escultura de Plumier (Iglesia de Notre-Dame de la Chapelle, Bruxelles) ${ }^{26}$, y la pintura de Juan Antonio Escalante, custodiada en el Gemäldegalerie (fig. 17), en Berlín, nos ofrecen una versión del tema, pero situando las figuras de forma invertida en relación a la de Miranda. En cambio, el cuadro de Valdés Leal, de la Colección del Convento de Carmelitas Calzados de Córdoba ${ }^{27}$, y el grabado de Mariette (BNM) se aproximan más en la distribución. Elías, tendido a la izquierda de la composición, es despertado por el ángel. No obstante, ninguno de los dos se puede considerar su antecedente o inspiración inmediata. Valdés Leal pone su acento en el movimiento ambiental, y Mariette desplaza a los dos personajes de la escena hacia el lado izquierdo, dando la primacía a un amplísimo paisaje.

Tras este análisis, insistimos en que la creación más próxima a la que examinamos, es la de Murillo, sin que esto quiera decir que Pedro Rodriguez de Miranda se inspirase directamente en él, sino que más bien ambos pudieron tener la misma fuente, un mismo grabado, dada la similitud temática.

\section{ELIAS PREDICE LA MUERTE DE OCOCÍAS, HIJO DE ACAD, QUE HABÍA CAÍDO POR LA VENTANA DE SU PALACIO}

El último lienzo de los pintados por Pedro Rodríguez de Miranda sobre San Elías, corresponde al mismo ciclo que el primero: a la lucha del profeta contra el rey.

Acad no sólo ofendía a Dios adorando a ídolos falsos sino también cometiendo atropellos y homicidios. Hizo lapidar a Nabot para apropiarse de su viña, próxima al palacio del rey (I R, XXI, 1-27). Pronto murió Acad

${ }^{24}$ Recogido en "Les Carmes imitateurs d'Elie (1370-1668)" en Les études carmelitaines, 1956, pág. 82 y ss.

25 Reproducido en la lámina 13 del Speculum.

26 Reproducida en la "Messe en l'honneur de Saint-Elie", Les études carmelitaines, 1956, pág. 148 y ss.

27 Estudiado por José VAlverde Madrio, "Dos pintores sevillanos en Córdoba", Catálogo ilustrado de la Exposición de Valdés Leal, celebrada por el Ayuntamiento de Córdoba, 1916, reproducido en la lámina 5 . 
y su hijo Ococias heredó el trono (I R, XXII, 29-52). Ococias no llevó una vida más ejemplar que la de su padre. Incurrió en los mismos delitos durante los dos años de su breve reinado.

Habiéndose caído de lo alto de la torre de su palacio, sito en Samaria, al asomarse a una ventana, envió a consultar a Baal-Zebúh para saber si él curaría. Elías salió al encuentro y le anunció que, porque había consultado a dioses falsos, moriría de sus heridas (II R, I, 2-17).

En la iconografía de los vicios, Ococías cayendo de la ventana de su palacio, es el símbolo del orgullo que duda ${ }^{28}$.

La escena (fig. 18) está identificada por una serie de símbolos y elementos parlantes bastante claros. El interlocutor de Elias ya no es Acad, que ha muerto, ni Ococías, que yace enfermo en el lecho, sino un ilustre emisario de éste. Como tal, no porta corona sino turbante, signo de su paganismo o judaísmo ${ }^{29}$. Como expresión de su nobleza se cubre con manto rojo y ciñe la espada a la cintura con banda del mismo color. Observemos que este color, que significa distinción y poder, sólo lo ostenta este personaje, como en el primer lienzo sólo lo lucia el rey y algún noble a su servicio. Soldados armados y otros súbditos forman su séquito de compañía y en representación del rey.

Elías, que ya había fundado su Orden y había «llamado» a Eliseo y a otros, también se hace seguir por ellos. Eliseo luce el mismo atuendo que su maestro, su barba y cabello blanco (que no su calva). La barba se considera tradicionalmente como símbolo de autoridad y poder patriarcal ${ }^{30}$; así como el hábito lo es de penitencia y austeridad, y el blanco de su capa de la inocencia y santidad de su vida ${ }^{31}$.

Por ser los dos protagonistas de la escena emisarios de Dios y del rey, respectivamente, y de rango paralelo, han sido representados en el mismo plano terrestre, mirándose frente a frente e intercambiando su mensaje y su oráculo.

La torre, de planta circular y con sucesivos pisos, abierta por ventanas, así como el muro del fondo, evocan el palacio donde reina Ococías y la torre desde cuya ventana cayó y enfermó.

28 REAU, obra citada, pág. 258 y 355.

29 Los verdugos de los mártires del cristianismo suelen llevar turbante, por ejemplo, en el "Martirio de Santiago", por Navarrete, en El Escorial. GALLEGo, obra citada.

30 Pérez Rioja, Diccionario de símbolos y mitos, Barcelona, Madrid, Tecnos, 1971.

${ }^{31}$ Juan-Eduardo CIRLot, Diccionario de simbolos, Barcelona, N. C. Labor, 1978. 
La torre es cilíndrica, no tiene la forma del zigurat babilónico, ni es de ladrillos como aquéllos. Es símbolo del poder y de la confianza orgullosa en la propia fuerza (que fue condenada en Babel y en la figura de Ococías). Expresa, también, la acción de elevarse por encima de la norma vital o social. En ella, el rey, en quien se cumple este simbolismo, lucha entre la vida y la muerte, víctima de sus propias ambiciones ${ }^{32}$.

La esbelta columna que sirve de pedestal a la estatua de Belzebub, nos recuerda la consulta hecha a este falso dios y la causa del enojo de Yahvé. Ella marca el punto más elevado, el confluyente de la atención de los protagonistas.

La expectación y el estupor que produce la predicación de Elías sobre la inminente muerte del rey queda expresivamente reflejado en los rostros y ademanes del emisario real y su comitiva.

La composición puede considerarse un tanto lineal, como friso histórico-narrativo y de asunto terrenal, o bien como una gran pirámide bajo la que se cobijan ambos bandos --el de Yahvé y el del rey-. didad.

Existe una sucesión de planos, que marcan aproximación o profun-

Según la tesis de Emilio Orozco Díaz, el que aparezcan figuras en primer término de las que sólo contemplamos el busto, significa que el artista ha realizado la composición introduciendo al espectador en ella (de forma imaginativa), y esto hasta tal extremo que los segundos planos pasen a primeros y primeros y principales. Mientras las figuras, teóricamente más próximas, casi desaparecen. Es un recurso buscado para lograr dar una prioridad, importancia y relieve a los dos protagonistas afrontados casi simétricamente, teniendo como eje la columna de Belzebub a quien el emisario real implora y Elías ataca.

Sigue siendo revelador y ostensible el lenguaje de las manos, principalmente el además de Elias que impone un tiempo de silencio, de escucha y reflexión. Momento que halla su eco y respuesta en el gesto de la figura de la derecha que lleva la mano a su barbilla en señal de extrañeza y consternación.

Este tema ha sido siempre menos acogido entre los artistas que los anteriores. Escasas son sus representaciones. Como fuentes no inmedia-

32 Chevalier y Gmeebrant, Dictionnaire des symboles, Paris, Seghers, 1974. Diccionarios Rioduero. Símbolos, Madrid 1983. PEREZ RIOJA, obra citada. CiRlot, obra citada. Morales y MaRin, Diccionario de iconología y simbología, Madrid, Taurus, 1984. 
tas podemos citar la pintura de José Jiménez Donoso («Fundación de San Juan de Letrán", Museo de Valencia) y principalmente el grabado número 22 del Speculum (fig. 19). En él Elías, en plena naturaleza, conversa con dos humildes emisarios esperando que su respuesta sea transmitida a Ococías. La dirección de la mano del profeta confluye con las lineas de fuga que se dirigen a la tienda en la que yace el rey. Lommelin, en éste como en los restantes grabados, dispone la escena con sencillez y claridad. Pasa a segundo término el punto de interés capital -la salud o muerte del rey-. Este recurso de dar la clave del cuadro a través de una escena de segundo término es usada también por Zurbarán y otros pintores.

Dos lienzos, dispuestos a derecha e izquierda, a la entrada de la capilla de Santa Teresa, obra de Pernicharo y Peña, respectivamente, completan, en cierto sentido, las cuatro representaciones de Pedro Rodríguez de Miranda sobre San Elías.

Su formato es diferente ( $3 \times 1,50 \mathrm{~m}$ aproximadamente) y su factura desigual entre sí. Hemos de tener en cuenta, no obstante, que el de Pernicharo ha sido recientemente restaurado con motivo de la Exposición «Carlos III y la llustración».

La figuración de estos lienzos alude a dos momentos diferentes, no relacionados entre sí. Pernicharo plasma el "Desafío a los profetas de Baal” (I R, XVIII, 20-40) y Peña la escena que ha inspirado mayor número de obras de arte, aquella en la que «Elías es arrebatado al cielo en un carro de fuego" (II R, II, 9-14). No nos detenemos en el comentario de ellos por no ser objeto de nuestro estudio, sólo queremos subrayar, dada su importancia, que la ascensión de Elías es imagen de la Ascensión de Cristo y que en la iglesia griega es asimilado a su homónimo el dios del sol (Helios), que recorre el firmamento en carro de fuego, de ahí su representación con este atributo ${ }^{33}$.

Antecedentes iconográficos pueden considerarse el mosaico cristiano del Mausoleo de los Julios, en el Museo Vaticano y el relieve de un sarcófago, conservado en el Museo de Letrán, en Roma, así como la pintura de Valdés Leal ${ }^{34}$, en los Carmelitas de Córdoba, y entre los innumerables grabados podemos citar el número 156 de la ya citada serie

Todos los diccionarios iconográficos interpretan estos temas.

VALVERDE MADRID, Catálogo ilustrado de la Exposición, obra citada, pág. 11. 
ER 1380 de la Biblioteca Nacional de Madrid, así como los de Ryckemans ${ }^{35}$ o el de Lommelin ${ }^{36}$.

Como conclusión y resumen de nuestro estudio podemos enjuiciar a Pedro Rodriguez de Miranda, por estos lienzos, como un artista de su época. Lo inscribiriamos dentro de la pintura barroca-clásica. Formado en la cultura simbólica de España, así como en todos los recursos pictóricos. Se mueve, quizá, en un ambiente refinado.

Respeta, en general, la ley de las tres unidades escénicas que se impuso en Europa en el siglo XVII no sólo en el teatro sino en las artes plásticas ${ }^{37}$.

En estos cuatro lienzos, agrupados dos a dos, encontramos que hay unos de mayor aparato, los que responden a la temática monárquica $o$ en su entorno, y otros, de mayor sencillez, que se agrupan en la serie de cuadros religiosos.

No podemos juzgar con precisión algunos valores, como los cromáticos, debidos al mal estado en que se encuentran los lienzos, faltos de limpieza y restauración. Aunque este defecto hace que el color quede diluido, la impresión que produce su coloración es agradable y apropiada, dominando las tonalidades cálidas.

35 Números 151 a 154, de la serie ER 1380, de la Biblioteca Nacional ce Madrid.

36 Lámina 26 del Speculum Carmelitanum, ya citado.

37 GaLlego, obra citada, pág. 292. 


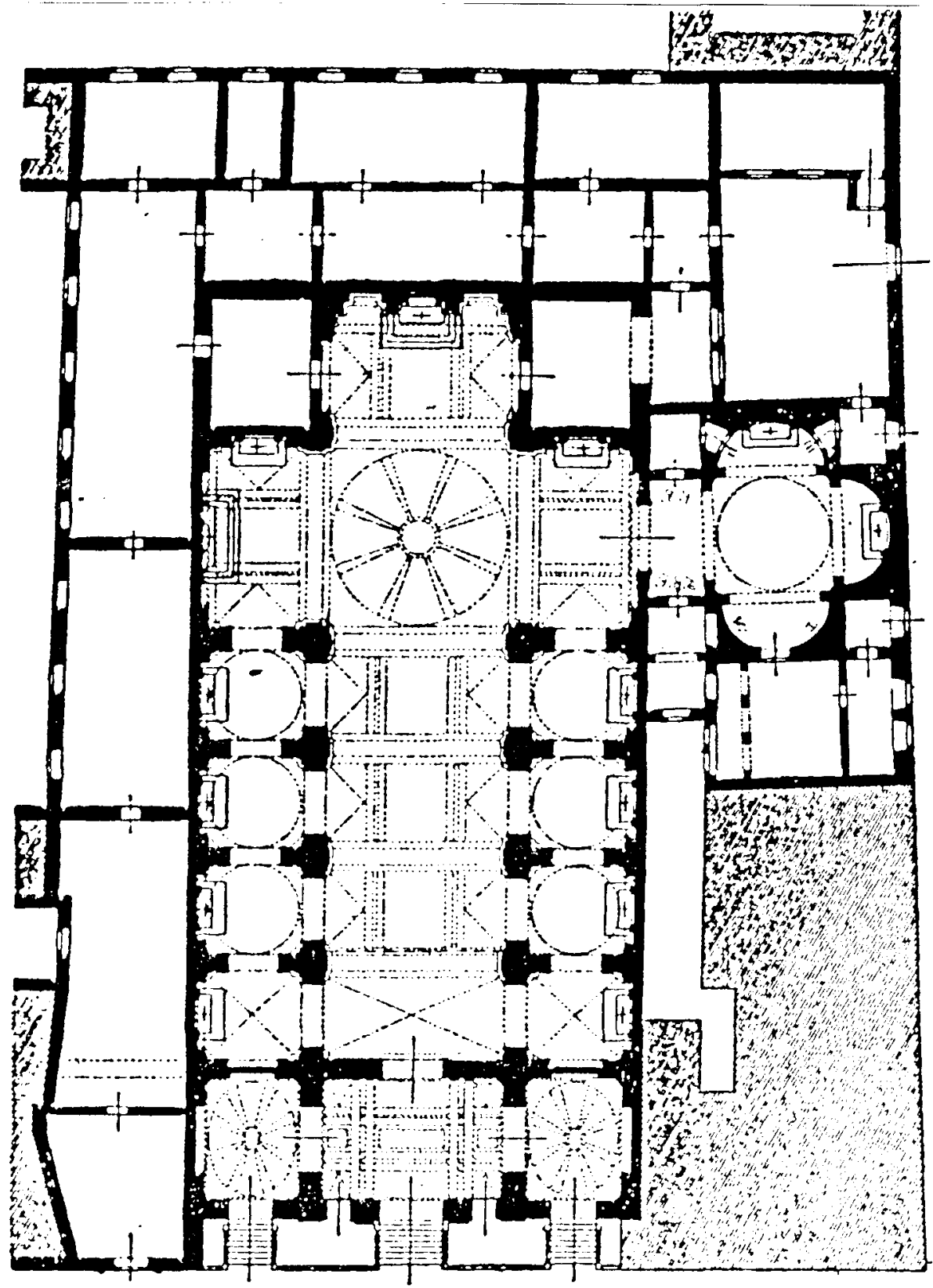

Fig. 1. Planta de la Iglesia de San Jose con la capilla de Santa Teresa. (Disposición de las pinturas de Rodriguez Miranda: Exedra izquierda: "l. Elías ante Acad" y "IV Elias con el emisario de Ococias". Exedra derecha: "ll Resurrección del hijo de la viuda de Sarepta" y "IV Elías reconfortado por el ángel"). 


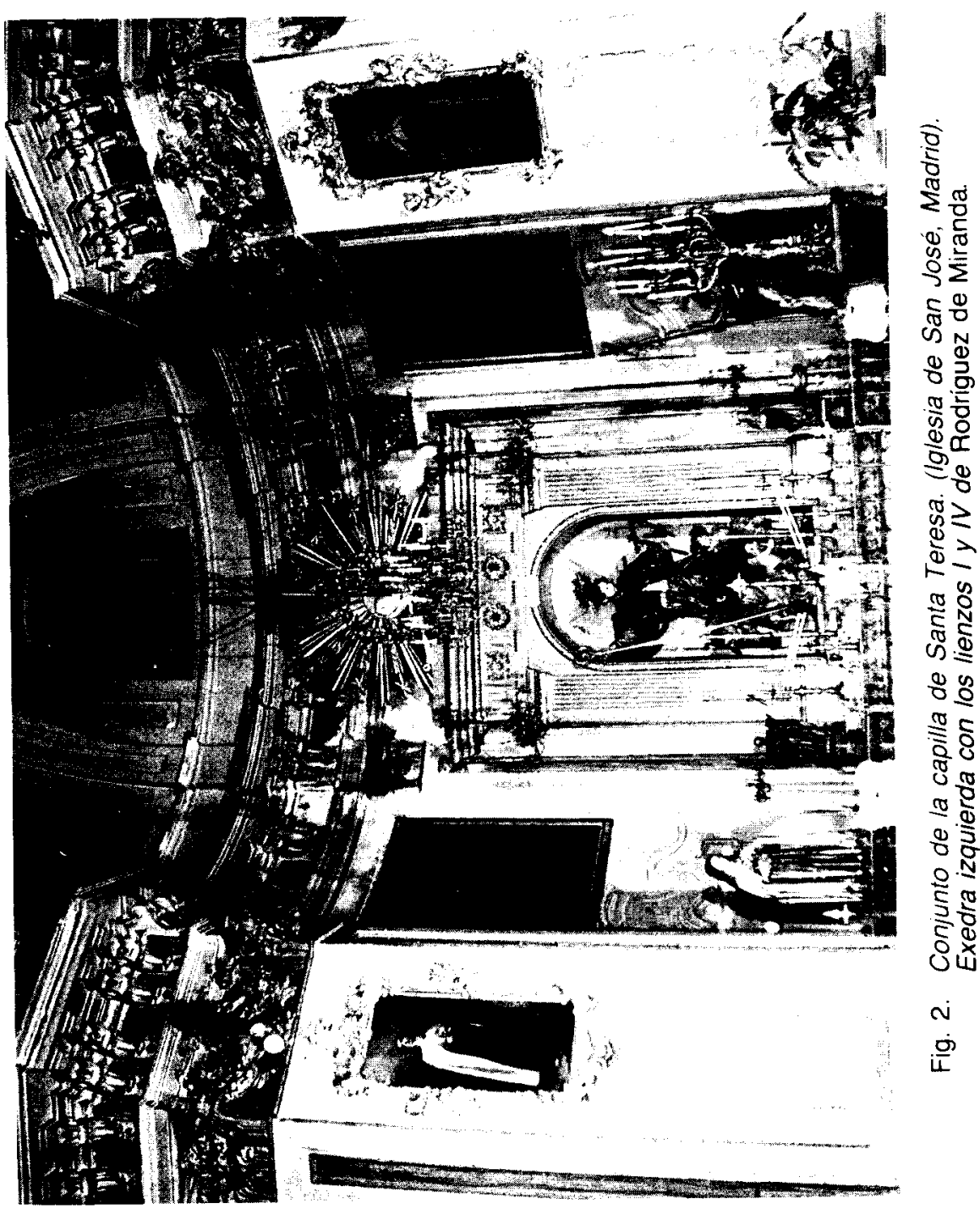




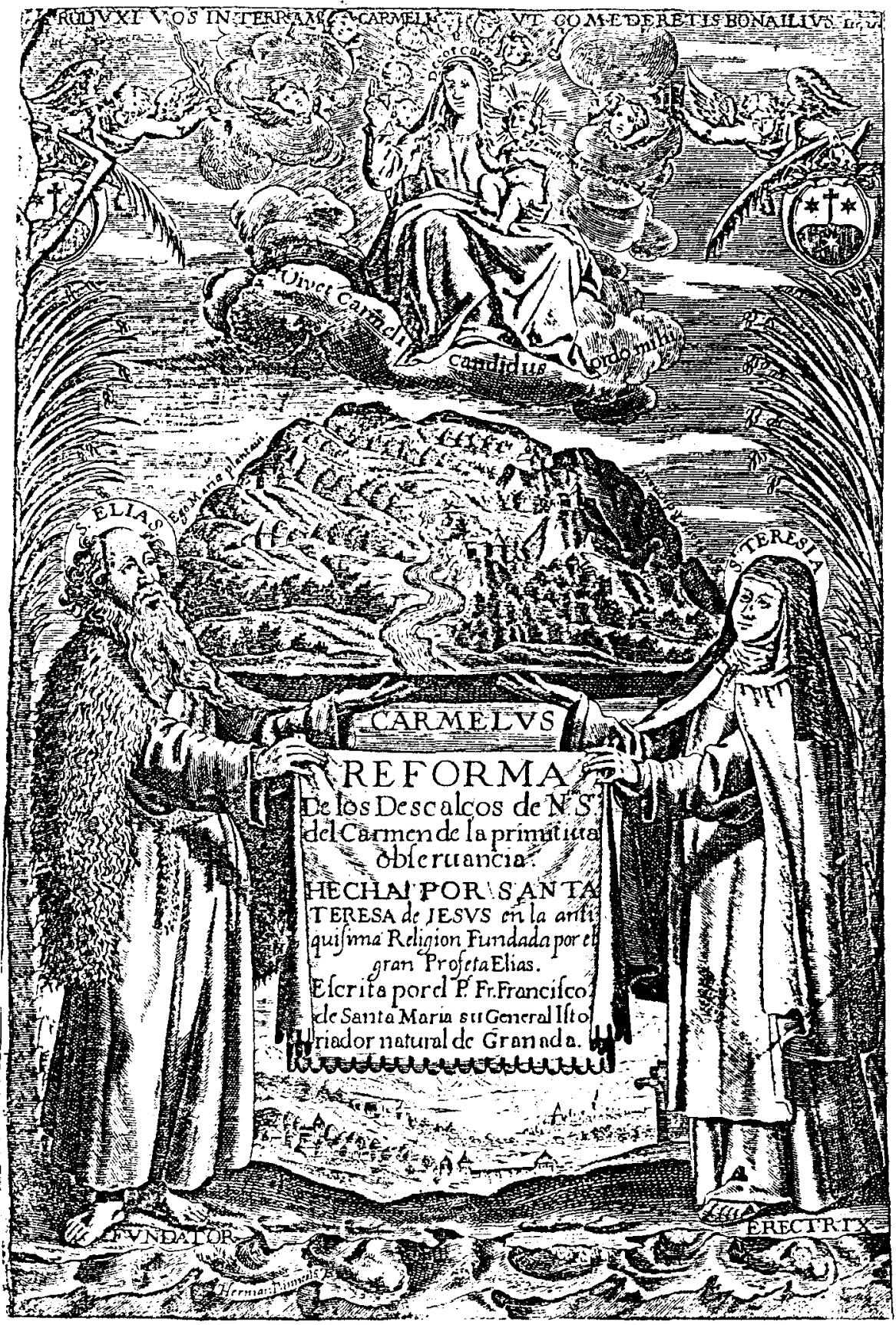

Fig. 3. Grabado de Hermann Pannels. 


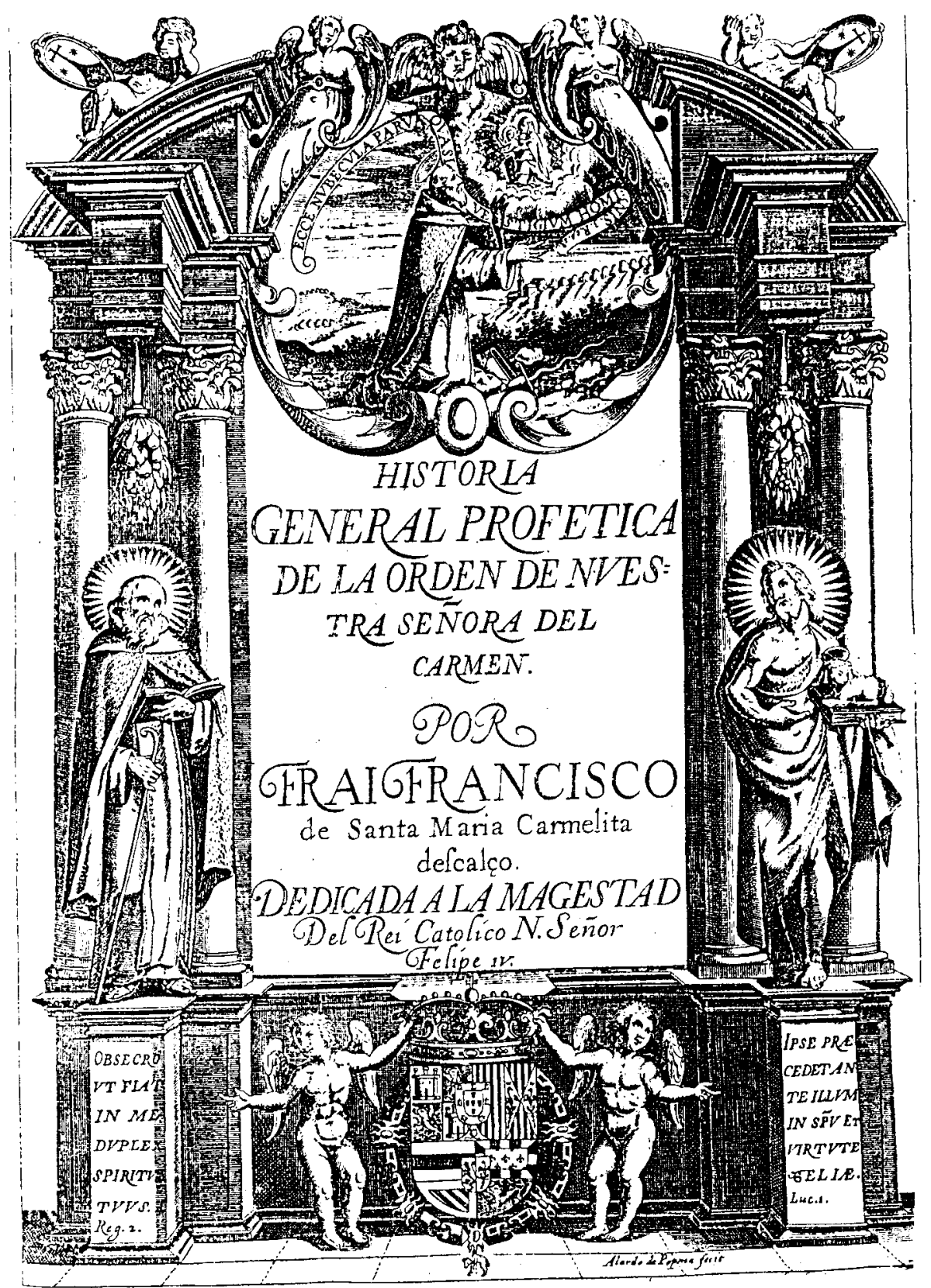

Fig. 4. Grabado de Alardo de Popma. 


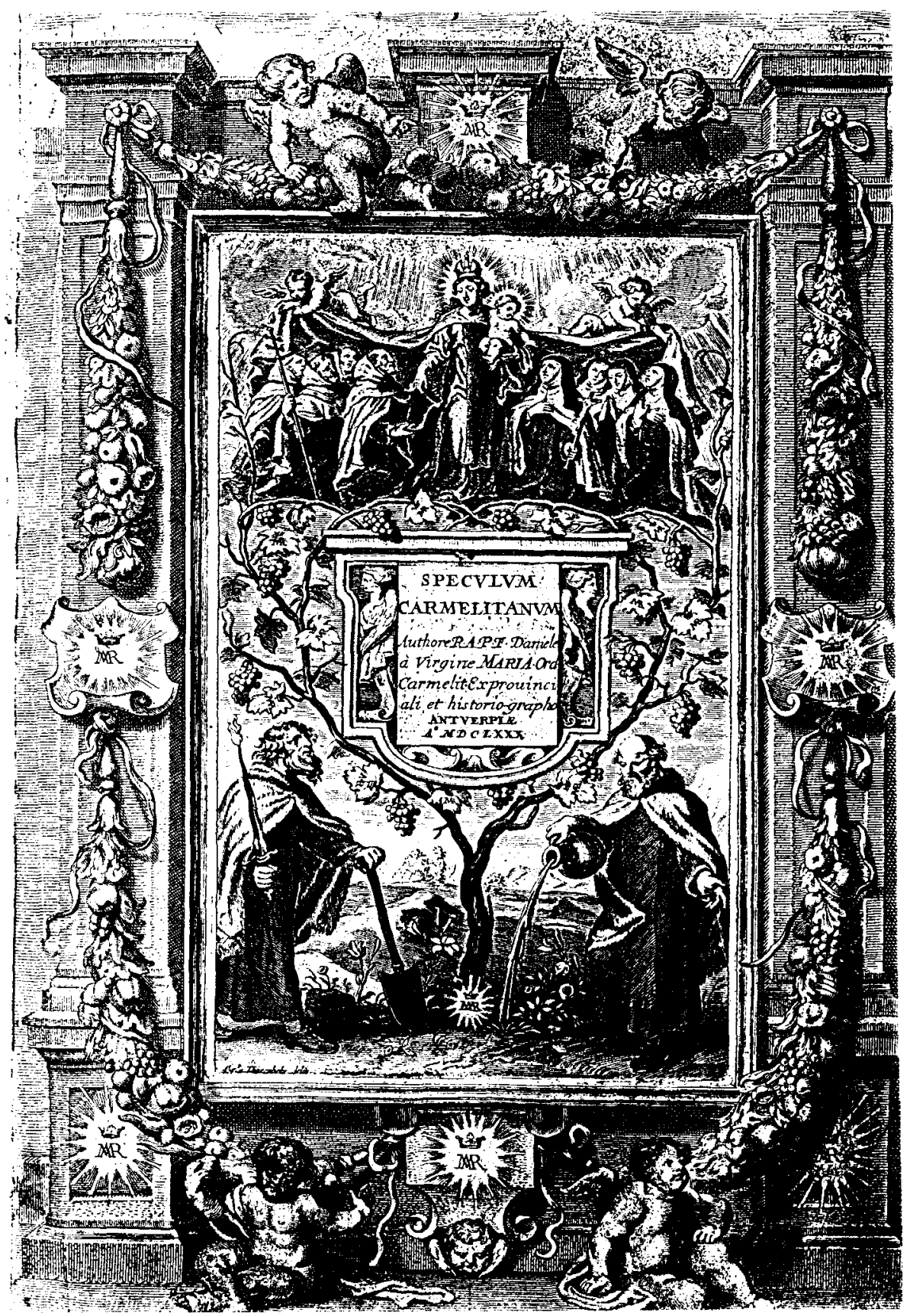

Fig. 5. Grabado de Lommelin Diepenbeke. 


\section{Un conjunto de pinturas de Pedro Rodríguez de Miranda}
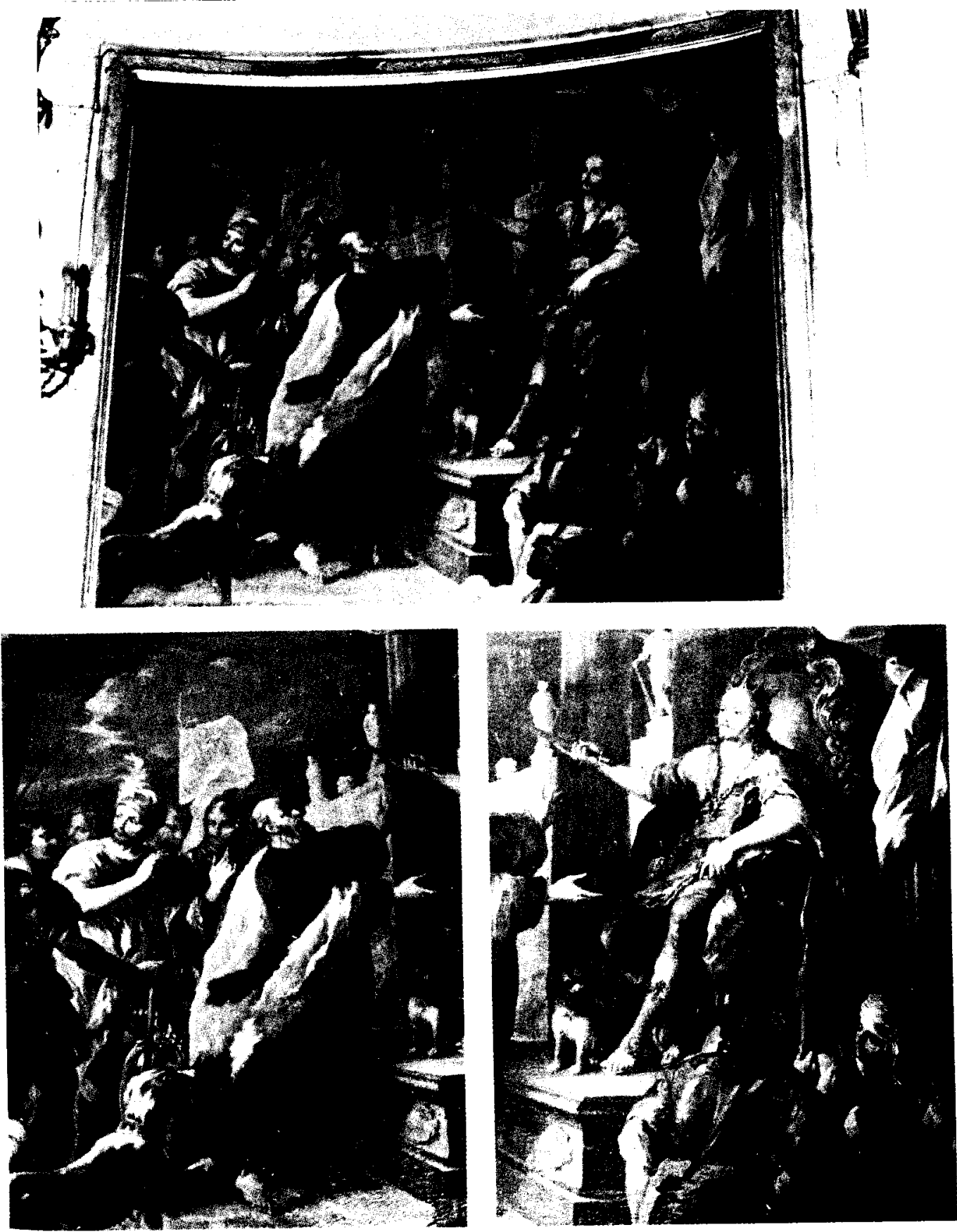

Fig. 6. "Elias ante Acad prediciendo la sequia", de Pedro Rodriguez de Miranda.

Capilla de Santa Teresa. Conjunto y detalles. 


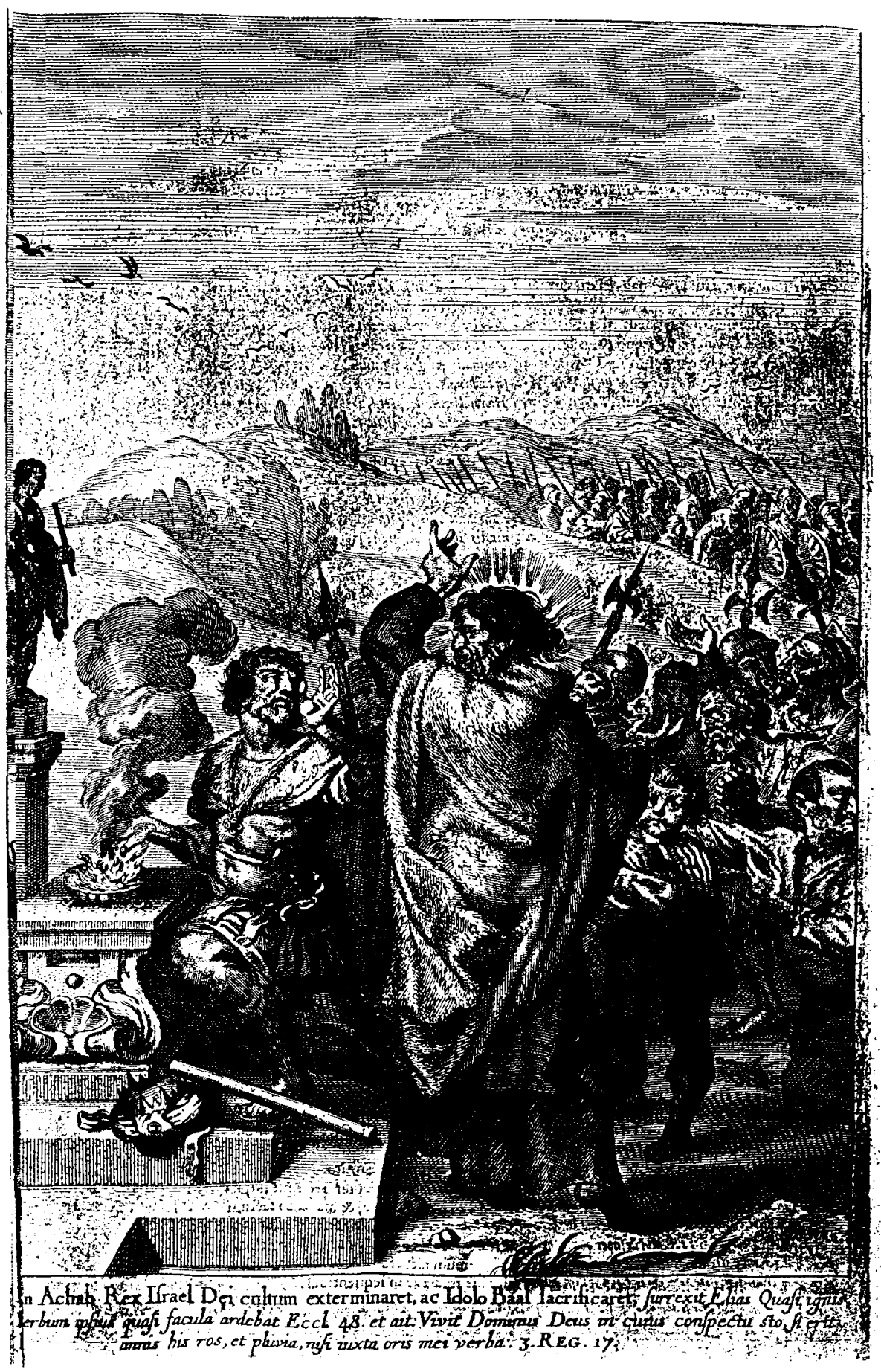

Fig. 7. Grabado de Lommelin Diepenbeke ( $0^{\circ} 4$ del Speculum Carmelitanum). 


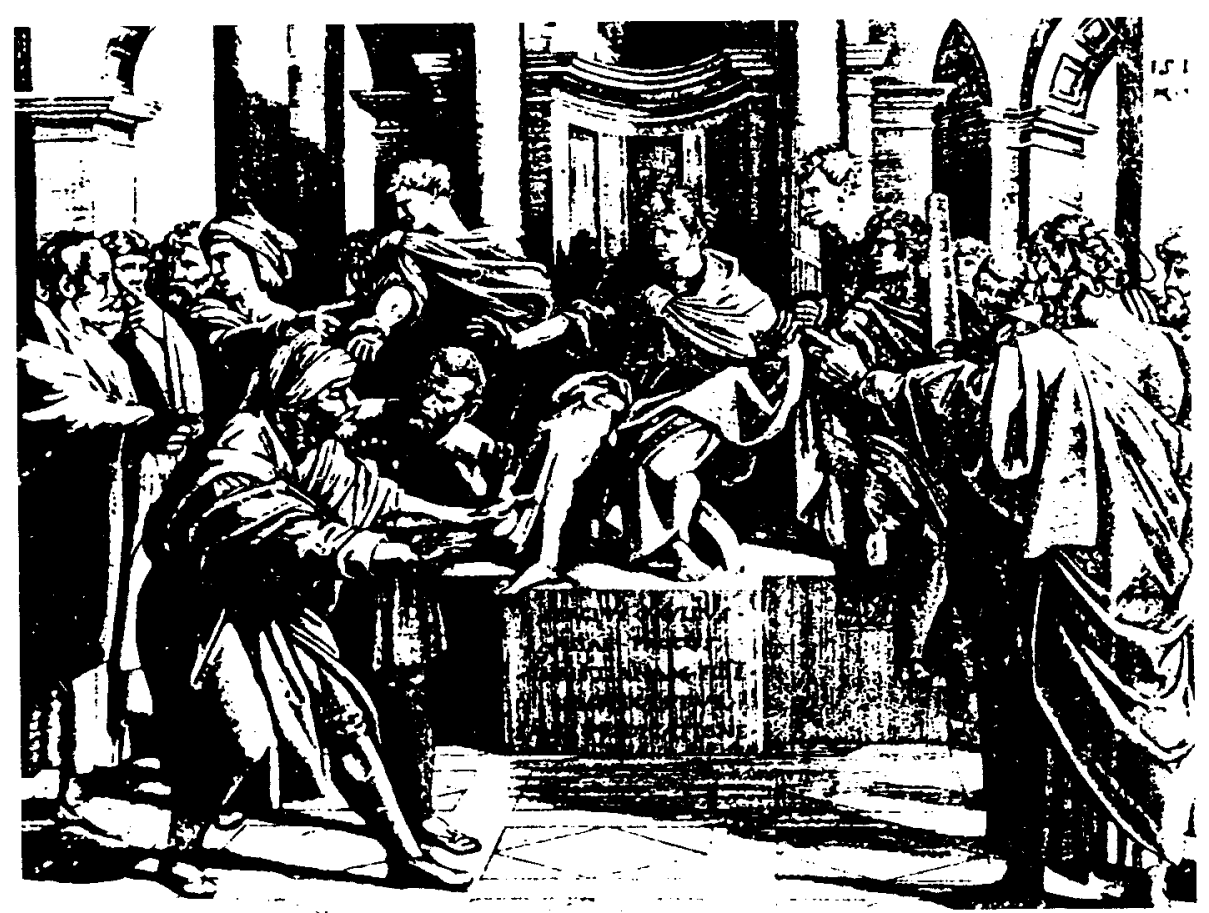

Fig. 8. A Venezianop, "Castigo de Elımas"

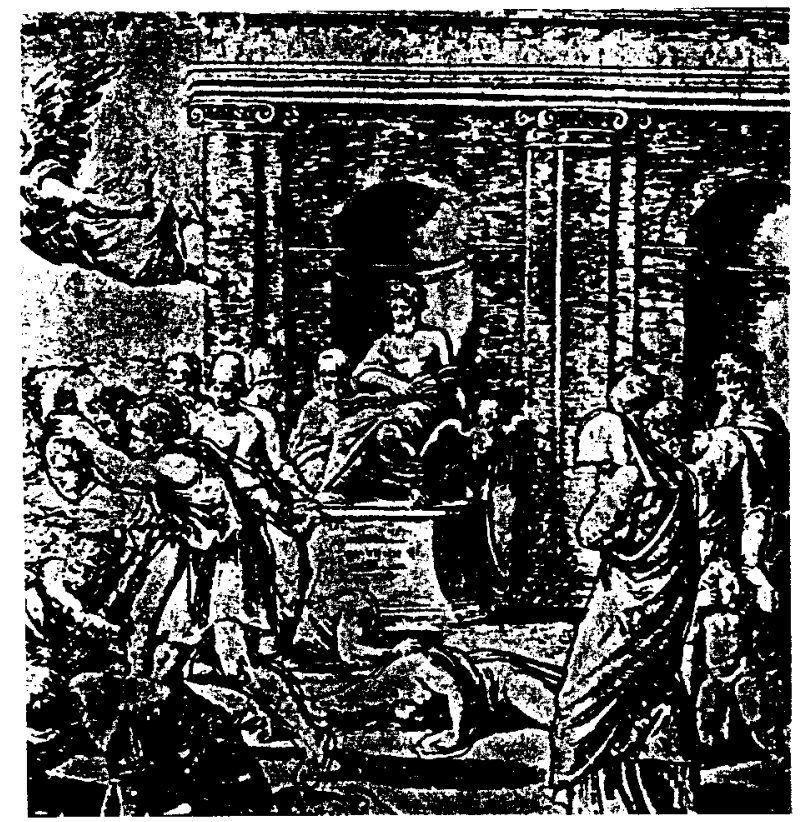

Fig. 9. Raimondi, "El martirio de Santa Cecilia". 


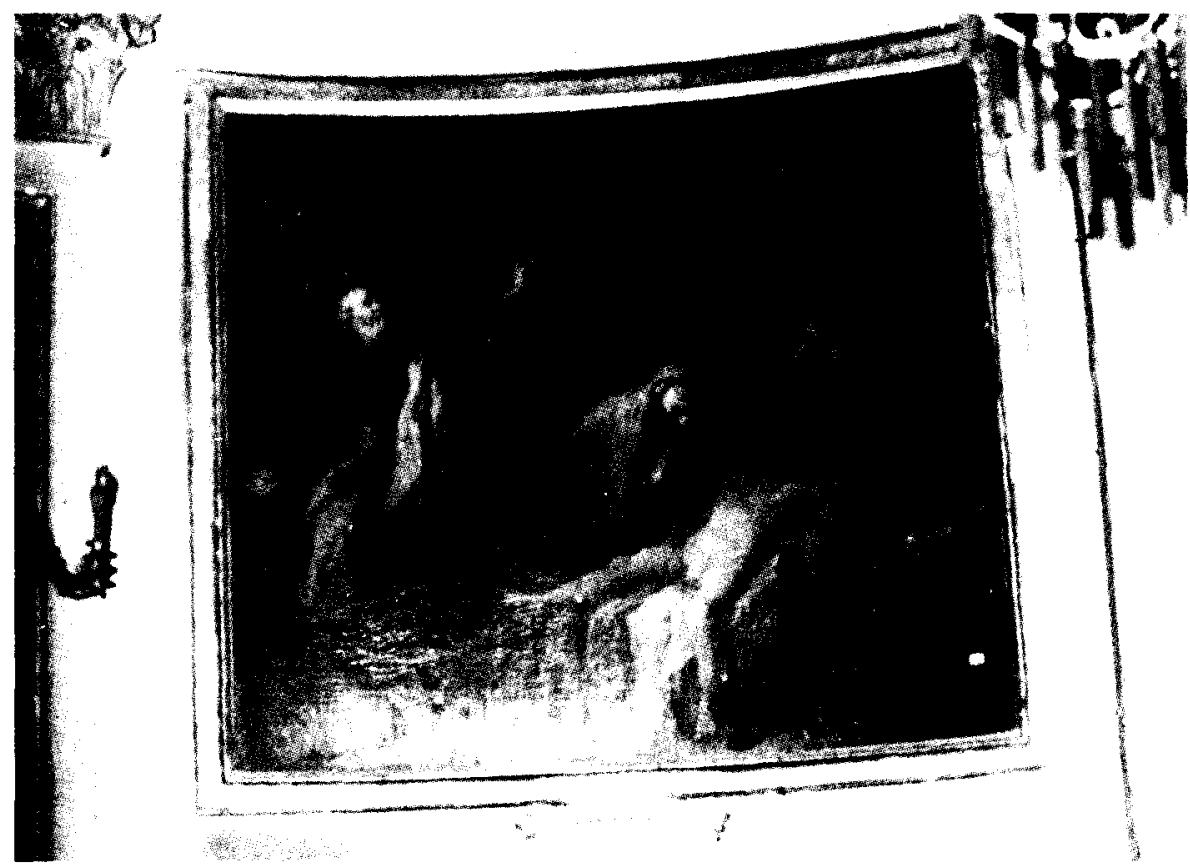

Fig. 10. "Elias resucitando al hijo de la viuda de Sarepta", de Pedro Rodriguez Miranda, Capilla de Santa Teresa. 


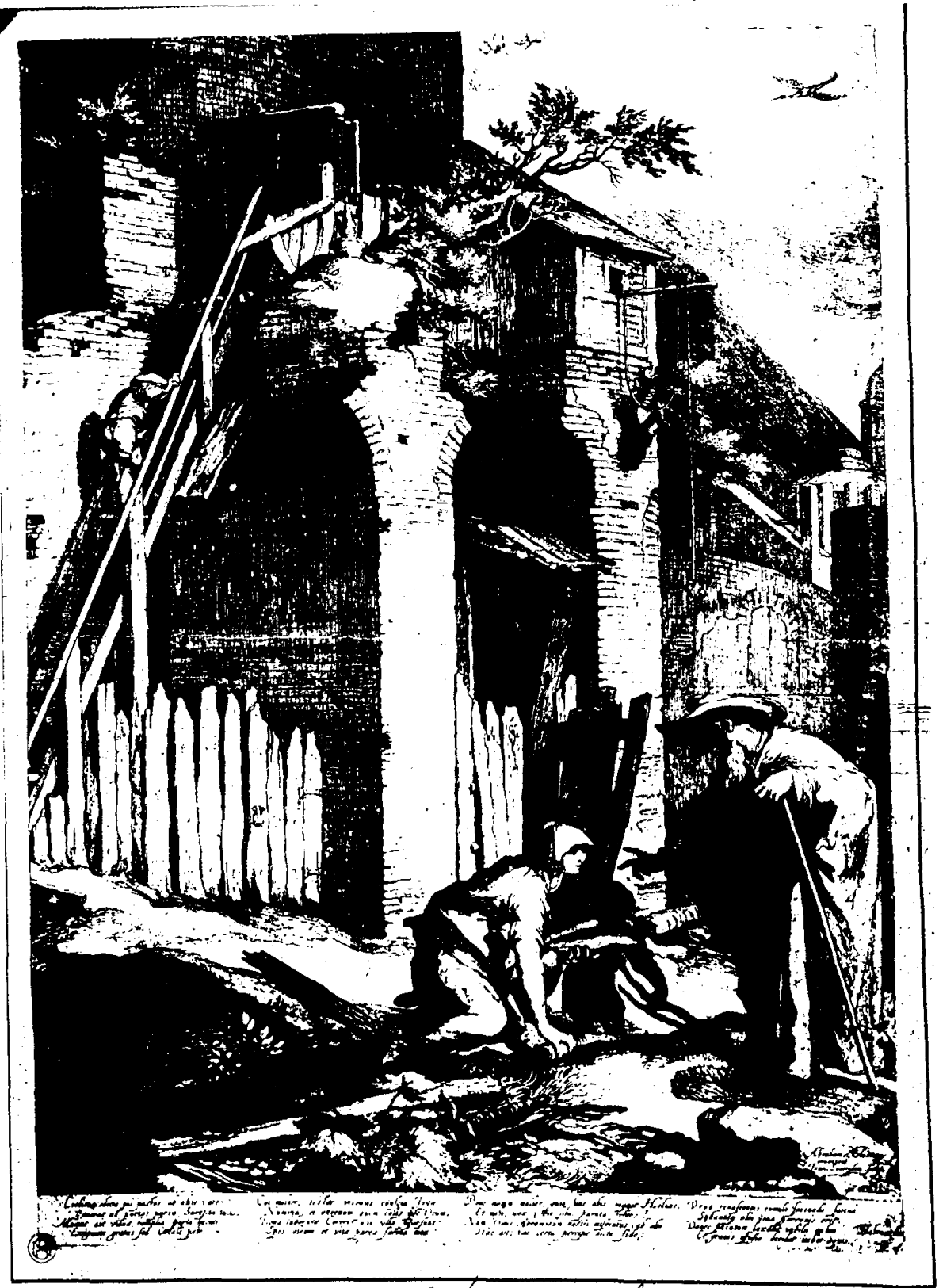

Fig. 11. Grabado de Abraham Blomero. "Elias ante la entrada de Sarepta". 


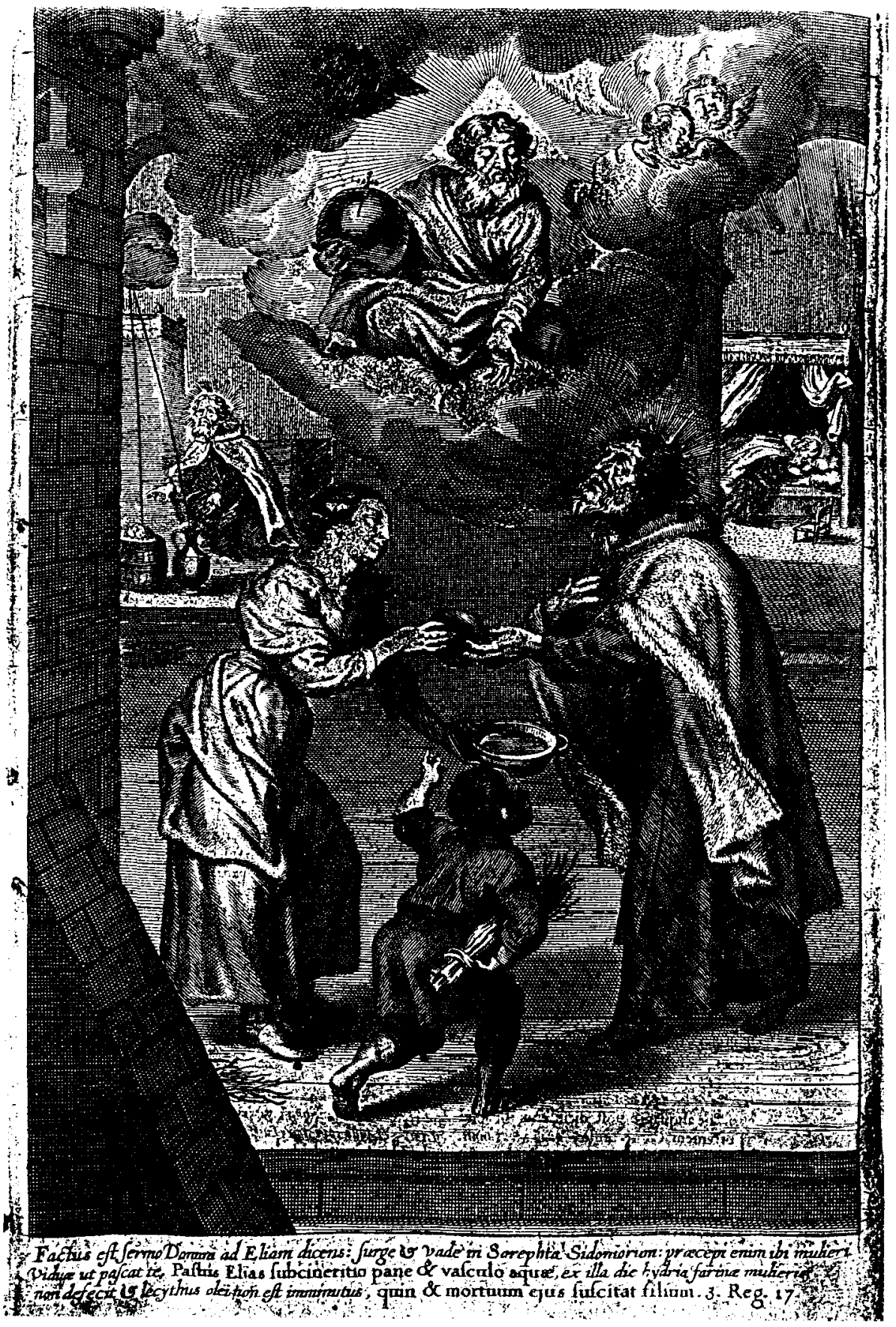

Fig. 12. Grabado de Lommelin (n." 7 del Speculum). 


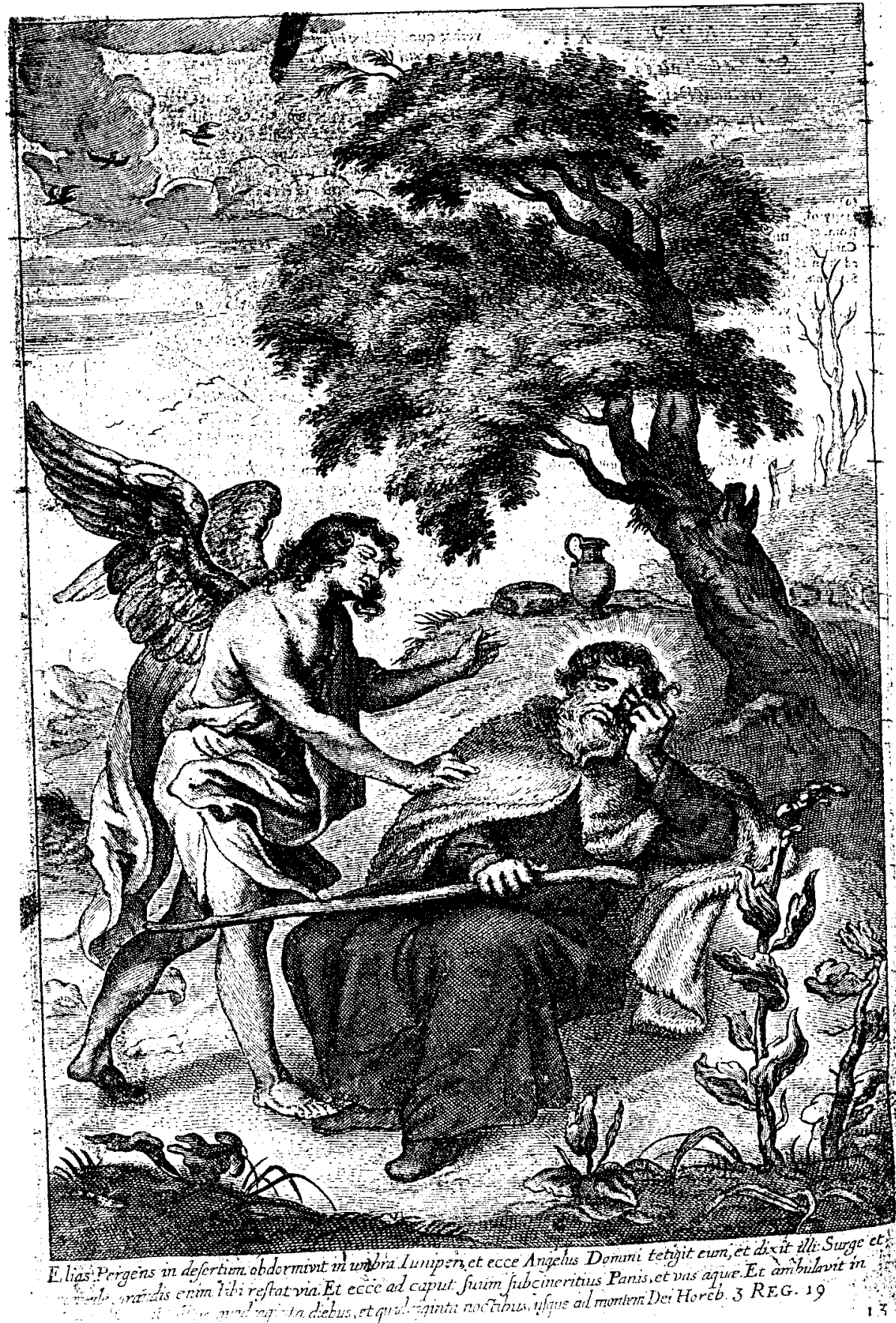

Fig. 13. Grabado de Lommelin (n." $13 \mathrm{del}$ Speculum). 


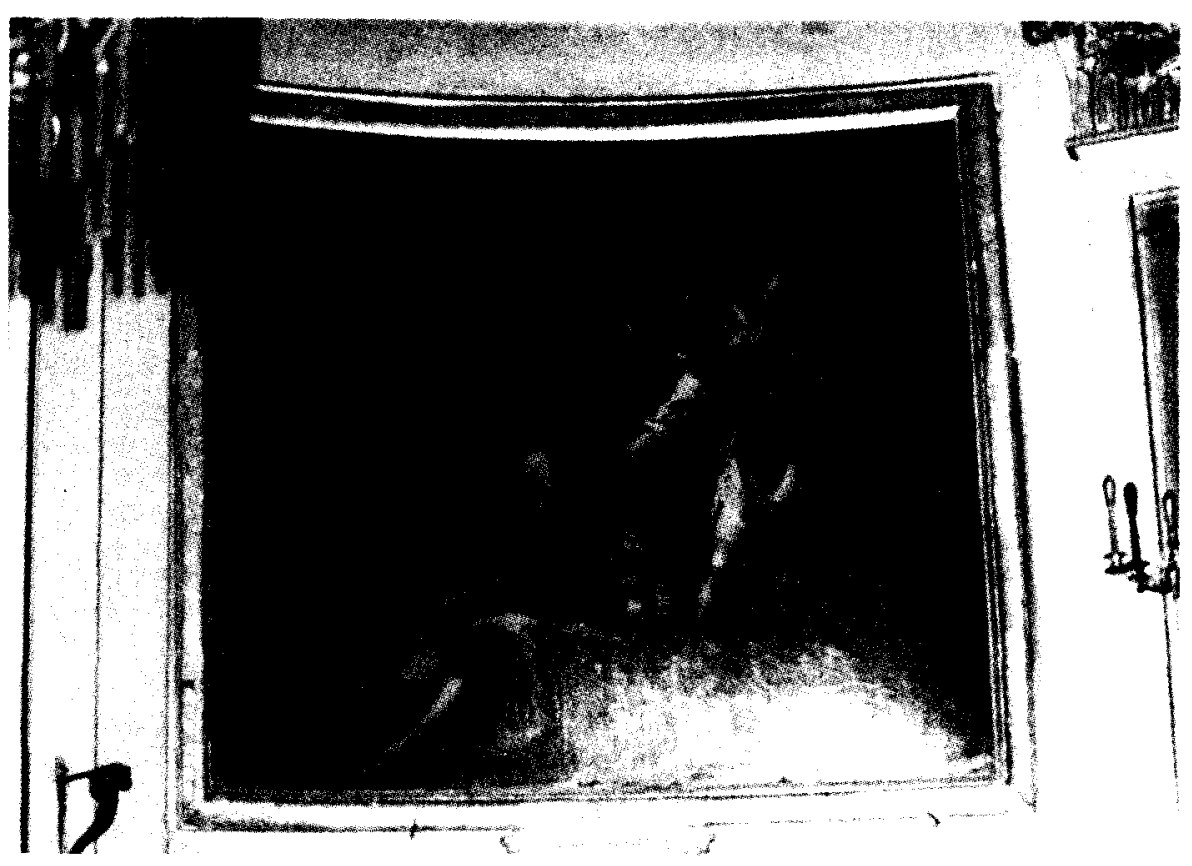

Fig. 14. "Un angel reconforta a Elias". de Pedro Rodriguez de Miranda. Capilla de Santa Teresa.

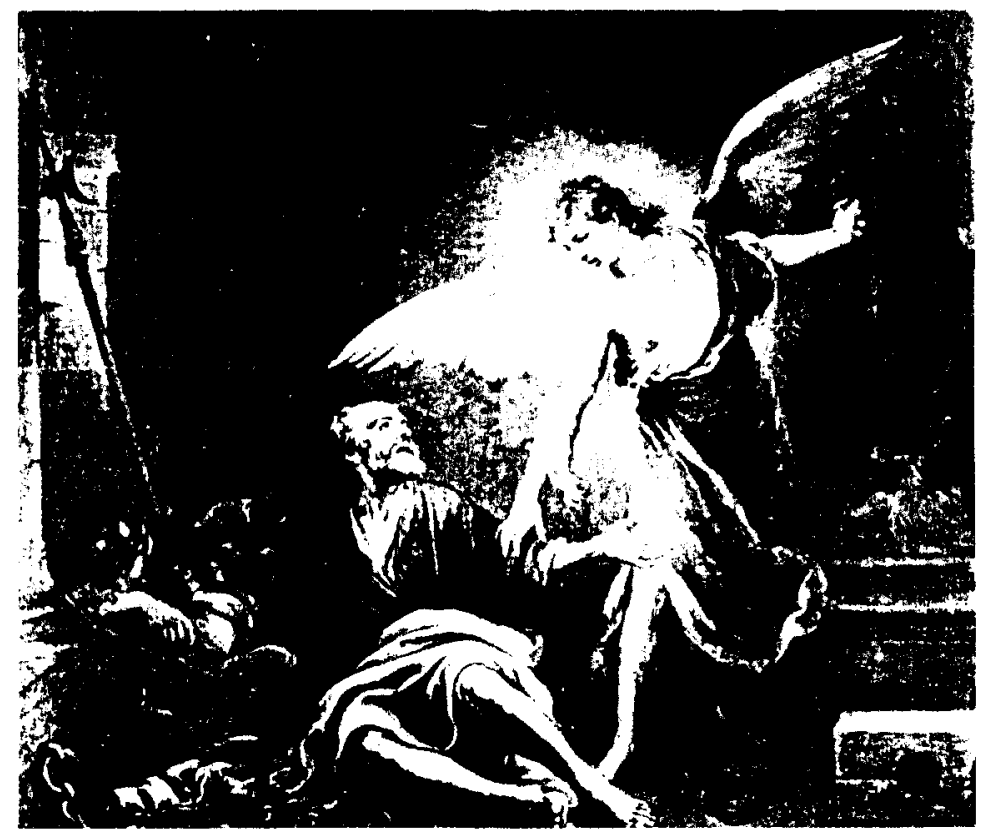

Fig. 15. Murillo, "San Pedro liberado por el angel". Leningrado, Ermitage. 


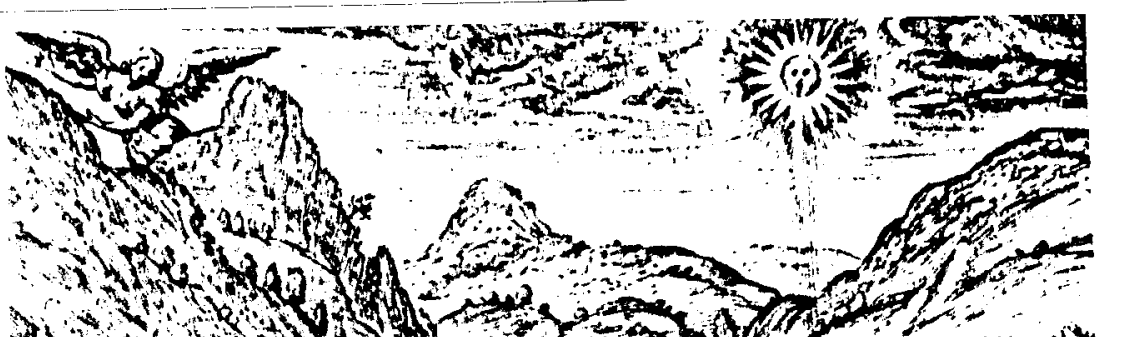

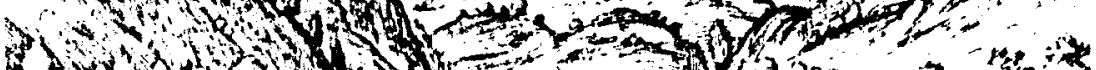

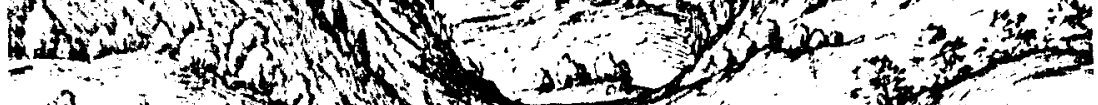

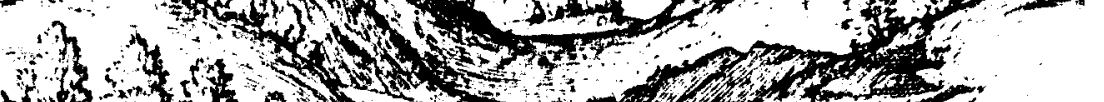

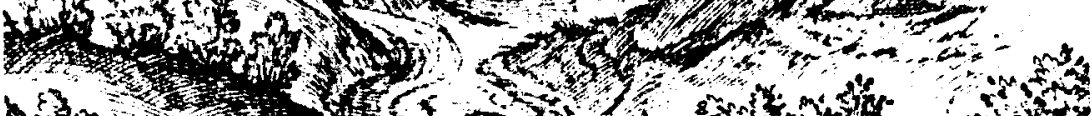

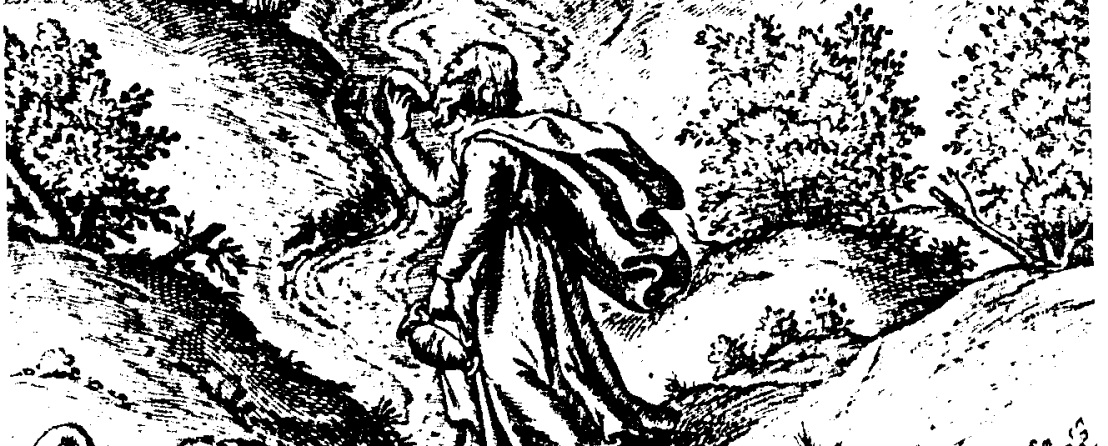
(6) a.

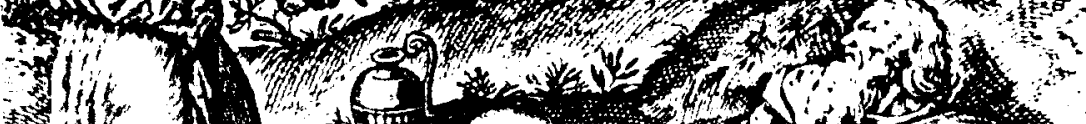

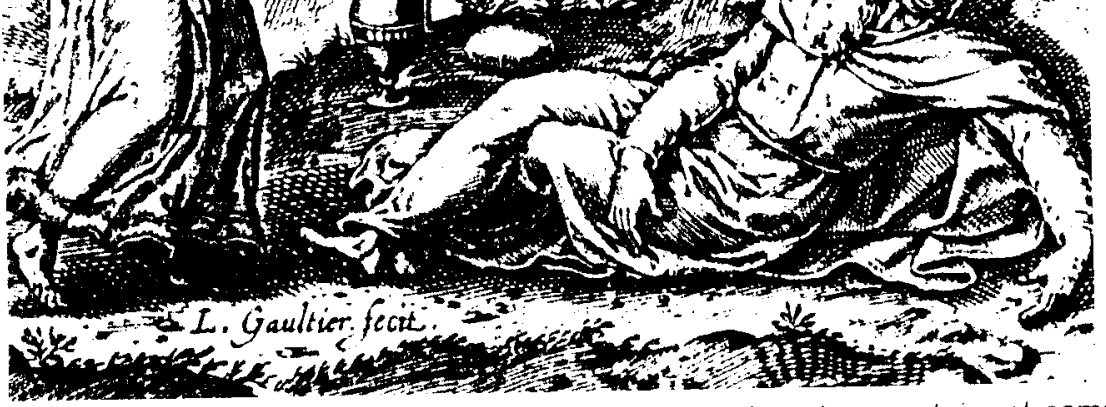

Fig. 16. Grabado de Leonardo Gaultier, "Elias reconfortado por el angel camina hacia el monte Horeb". 


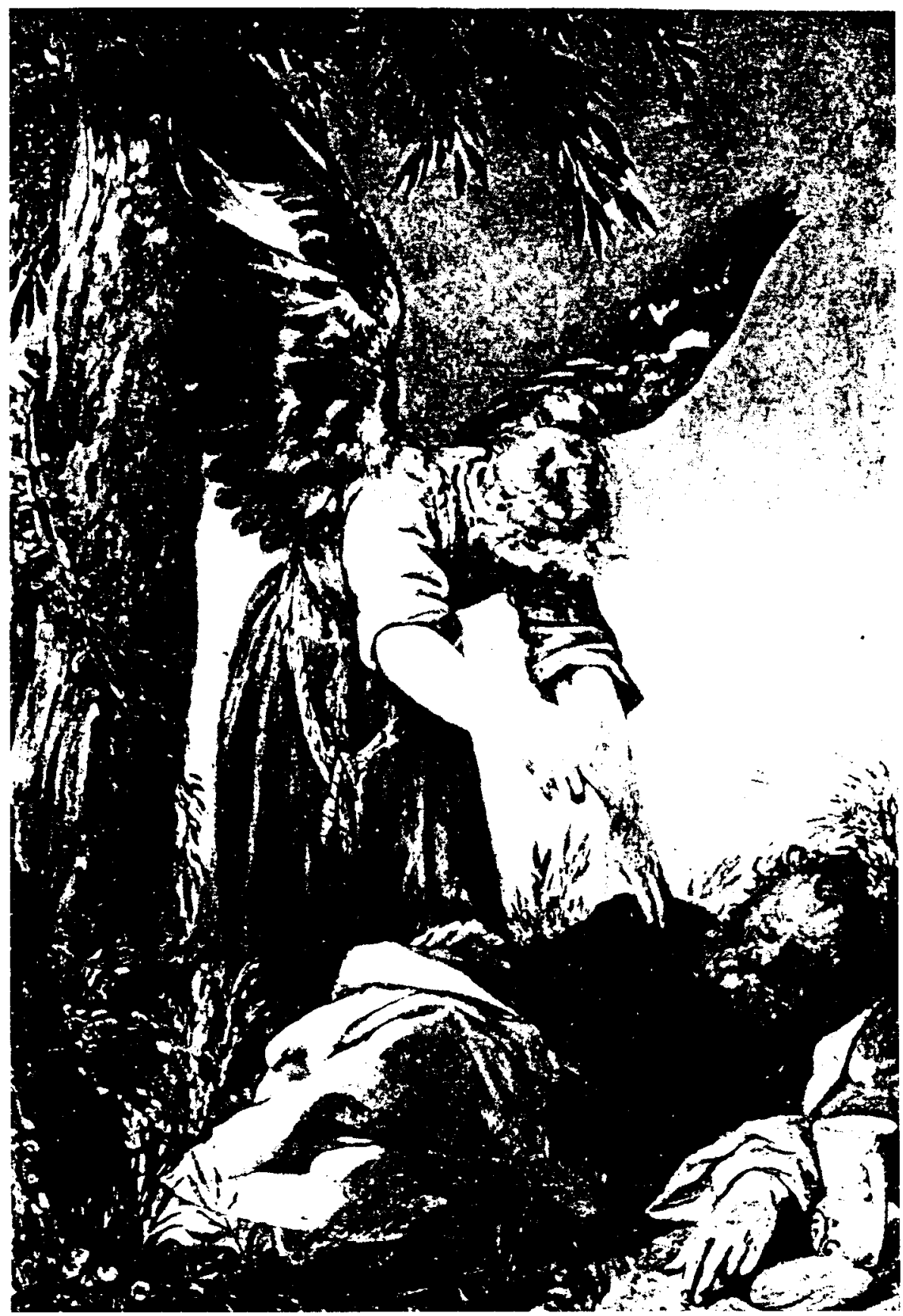

Fig. 17. Juan A. Escalante, "Elias despertado por el ánge/». Berlín, Gemäldegalerie. 

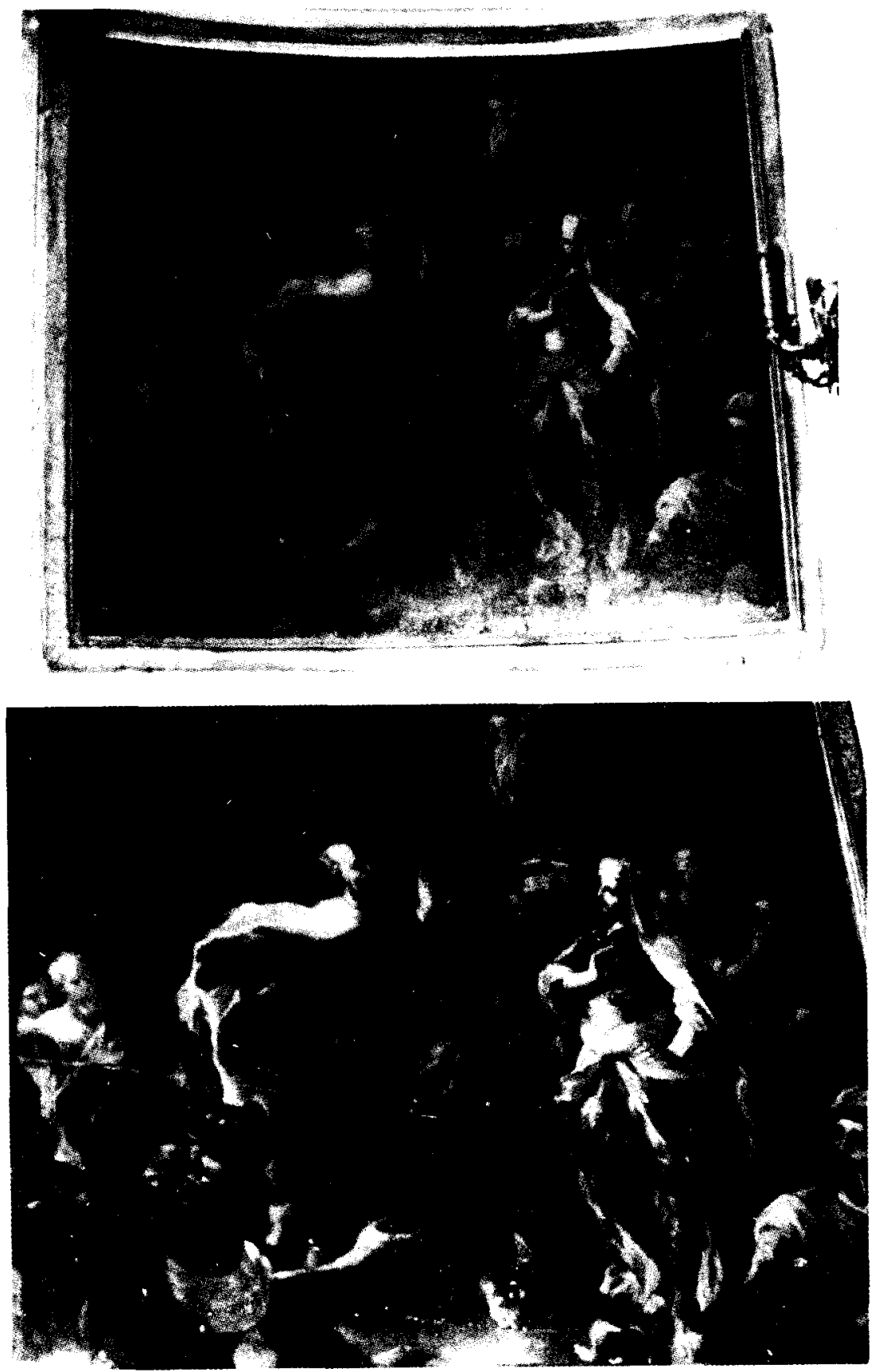

Fig. 18. "Elias ante el emisario del rey", de Pedro Rodriguez Miranda. Capilla de Santa Teresa. 


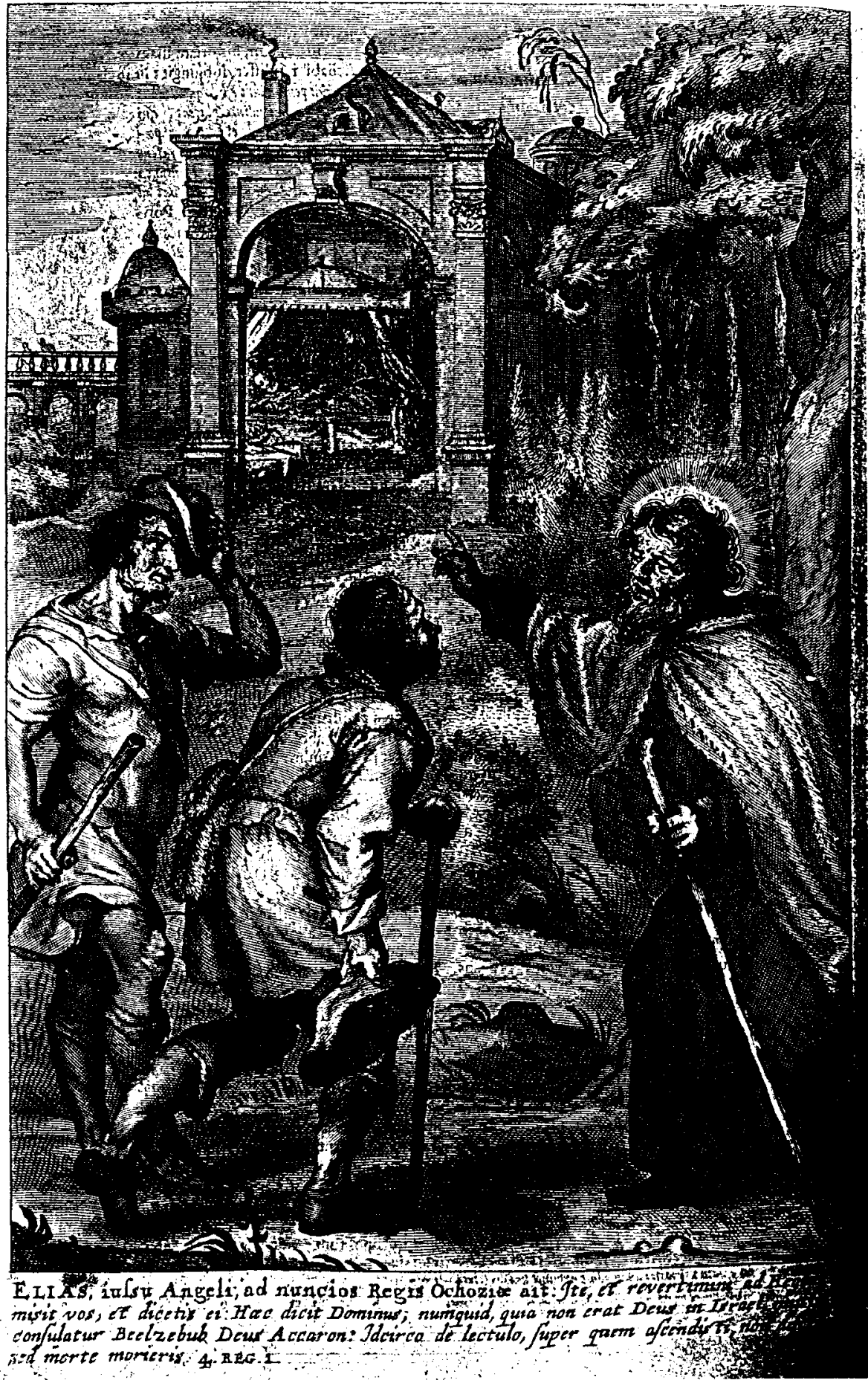

Fig. 19. Grabado de Lommelin (n. 22 del Speculum). 